IMPROVING ADOLESCENT GIRLS'ARGUMENT WRITING: A TIER 1 SELFREGULATED STRATEGY DEVELOPMENT INTERVENTION IN A NEW ZEALAND SECONDARY SCHOOL SOCIAL STUDIES CLASSROOM

\author{
BY \\ KATHRYN HUTCHINSON
}

A thesis submitted to the Victoria University of Wellington in fulfilment of the requirements for the degree of Master of Education

Victoria University Wellington

2017 
Improving Adolescent Girls' Argument Writing: A Tier 1 Self-Regulated Strategy Development Intervention in a New Zealand Secondary School Social Studies Classroom

\begin{abstract}
Self-Regulated Strategy Development (SRSD) is a model of writing instruction with a convincing evidence base (Santangelo, Harris \& Graham, 2016). The present study examines why SRSD is more effective for some students than for others. A mixed methods one-group prepost design was used to compare writing performance, writing self-efficacy, self-regulation for writing, and knowledge of argument writing. The whole-class $(n=27)$ wrote argument essays using an SRSD writing instruction method, in an urban multicultural New Zealand secondary school. Students completed the following digital scales and questionnaires: a writing selfefficacy scale, a self-regulation aptitude for writing scale, and writing knowledge questionnaires pre- and post-intervention. Following the quantitative phase, where students showed gains in argument writing, interviews were conducted with a sample of students who showed low, moderate and high gains in argument writing. Results indicate that while SRSD instruction in argument writing improves writing performance generally, transcription issues can be barriers to writing progress, as can issues with ideation and self-regulation. This Tier 1 SRSD intervention contributes to the SRSD writing research in that it supports the global generalisability of the SRSD method in teaching argument writing, and evaluates reasons for its relative effectiveness.
\end{abstract}




\section{Contents}

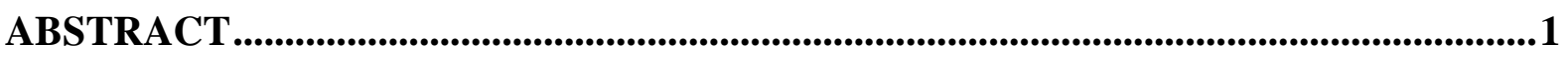

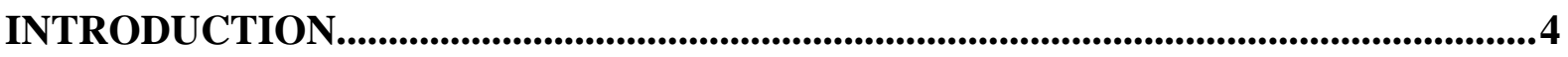

THEORETICAL BACKGROUND ....................................................................................5

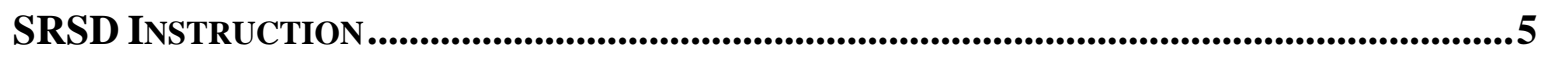

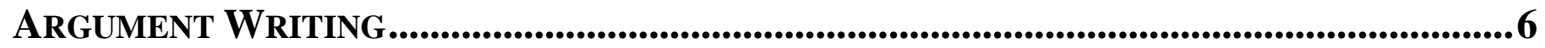

Writing SELF EFFICACY AND WRITING SELF-REgUlation ...............................................7

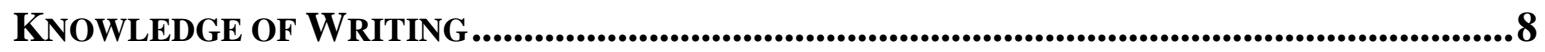

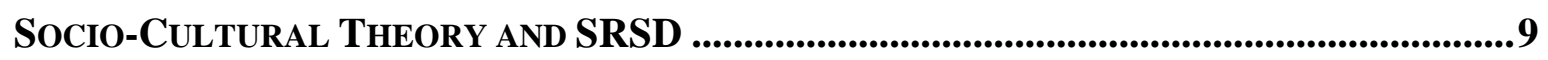

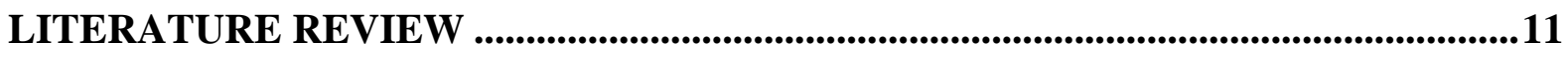

THE PRESENT STUDY .................................................................................................24

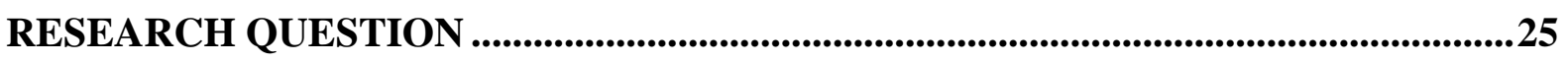

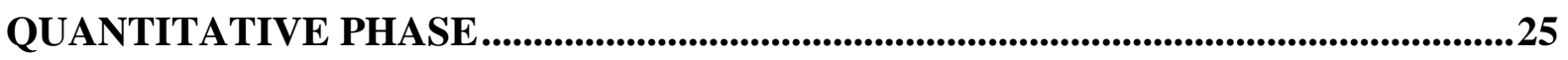

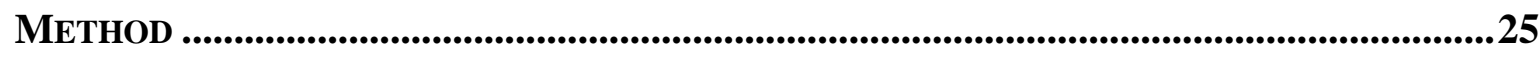

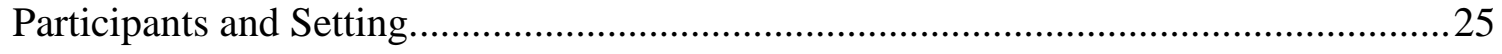

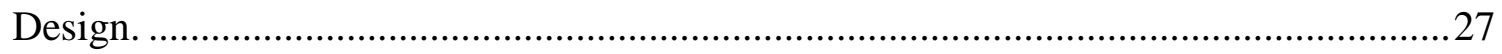

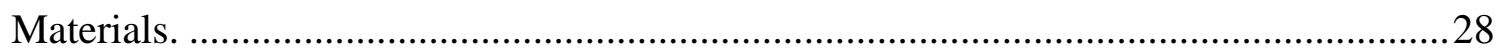

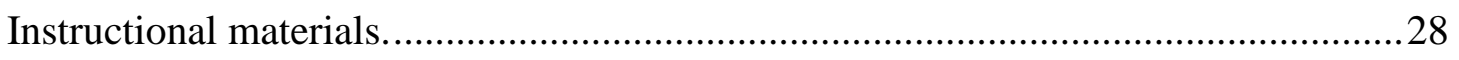

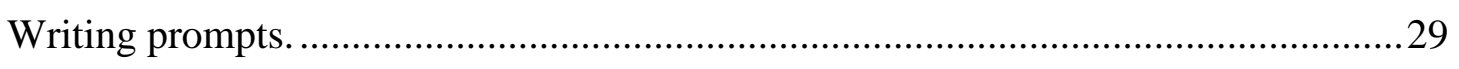

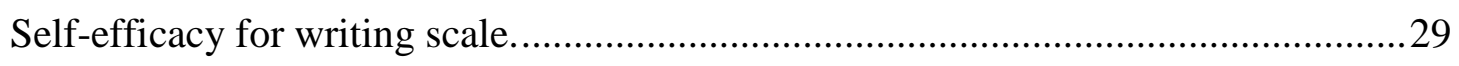

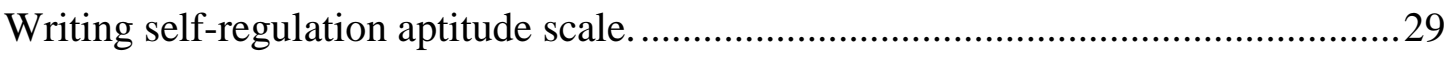

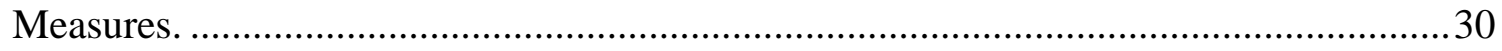

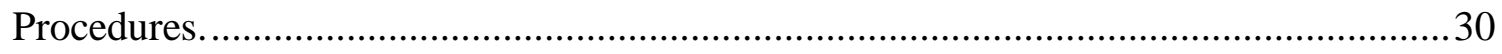

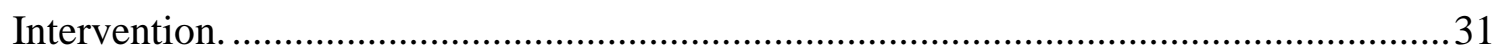

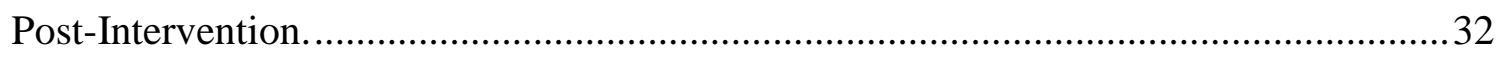

TREATMENT FIDELITY ..........................................................................................................33

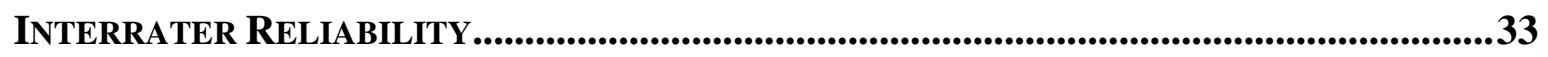

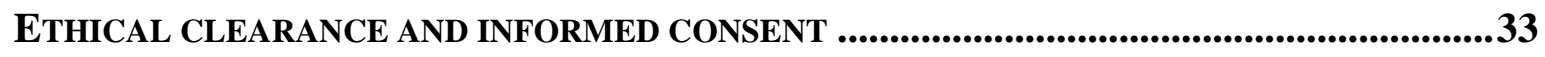

RESULTS AND DISCUSSION

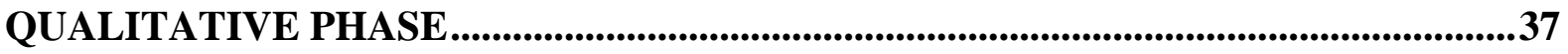




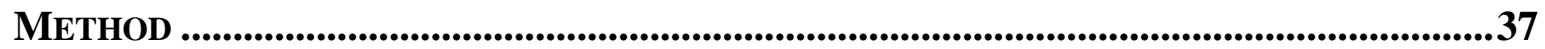

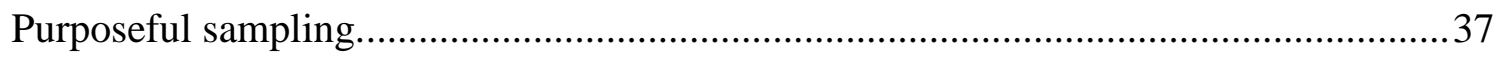

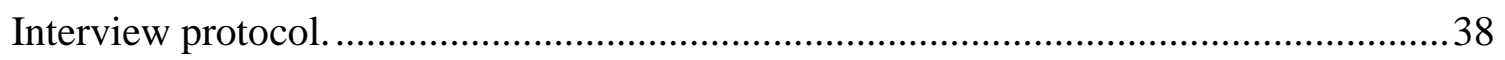

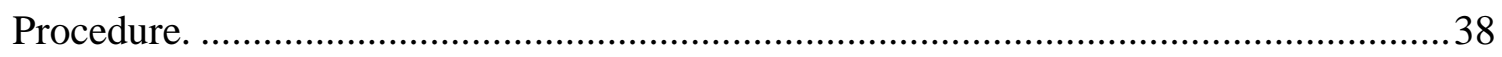

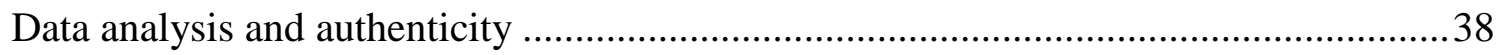

RESULTS AND DISCUSSION ........................................................................................39

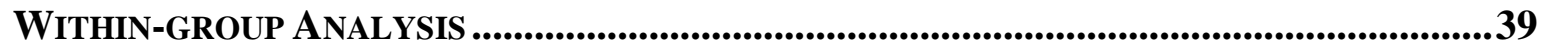

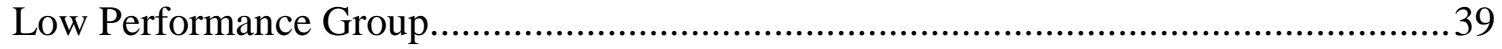

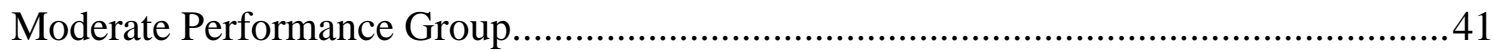

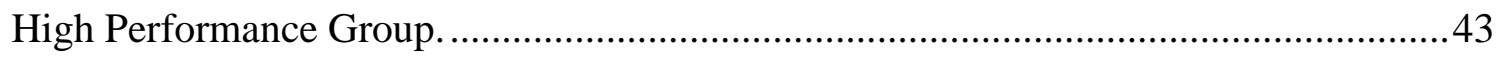

ACROSS GROUP COMPARISON ...................................................................................................45

INTEGRATION OF THE QUANTITATIVE AND QUALITATIVE RESULTS ..........47

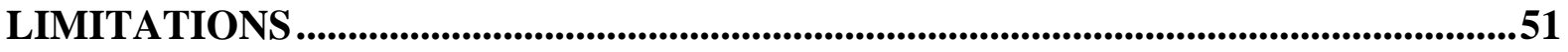

FUTURE RESEARCH DIRECTIONS ...............................................................51

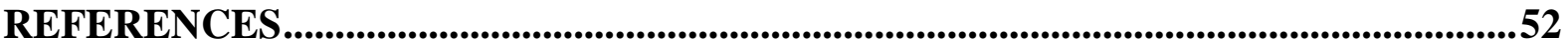

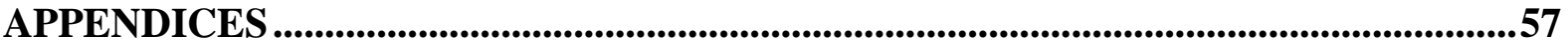




\section{Introduction}

Writing is a critical skill required for the successful attainment of high school qualifications and for successful work and employment outcomes. Writing is a highly complex and demanding process, one of the most difficult skills that students are required to learn (De La Paz \& Graham, 2002). When students can ably present their thinking in writing, they are equipped to demonstrate their knowledge and understanding of what they are learning in the increasingly challenging formal assessment environment. The expectation that understanding will be demonstrated through written representation remains the norm in educational assessment practice. However, national educational outcomes for the Ministry of Education in New Zealand (Ministry of Education, 2016) indicate that more than 25\% of students enter high school without the writing skills necessary for success at the expected level. Given that the Ministry of Education expects that $85 \%$ of the student population to be at or above the National Standard by 2017 (Ministry of Education, 2016), a targeted approach to writing skill development is important.

Research indicates that secondary school students spend only a limited amount of time writing in class, and that teachers-in-training and teacher practitioners devote minimal learning time to the craft of writing (Applebee \& Langer, 2011; Wilcox \& Jeffery, 2015). Many students enter high school without a positive approach to writing. Teachers perhaps respond to this by providing learning experiences that do not include regular writing tasks (Harris, Graham, Mason \& Friedlander, 2008). However, the neglect of writing skills, especially in junior high school, can negatively affect future success in formal written assessments and educational options. When students lack confidence in their writing capacities, they can lose enthusiasm for learning in challenging subject domains (Harris, Graham, Mason \& Friedlander, 2008). Social Studies is one such domain.

The present study investigated the use of explicit writing strategy instruction on students' learning of subject area material. Specifically, one teacher worked with a whole class (Tier 1) of Year 9 Social Studies students using Self-Regulated Strategy Development (SRSD) to develop skills in argument writing. This involved increased opportunities for writing practice, and access to complex source material, so that student ideas could be supported with relevant evidence. 


\section{Theoretical Background}

SRSD is an evidence-based approach to instruction that was developed in the early 1980's (Harris, Graham, Mason \& Friedlander, 2008). It was designed as a practical tool for teachers and is grounded in social cognitive theory (SCT) (Bandura, 1986). According to SCT, there is a triadic relationship between personal, behavioural and environmental influences, known as reciprocal determinism. Personal factors, such as beliefs about one's capabilities, affect behaviour and individuals' interpretation of environmental cues, such as feedback from others. For instance, two students who receive feedback about a writing performance may interpret the feedback differently, and which may affect their future writing performance. Thus, individuals are agentic in their environments while being both products and producers of that environment (Bandura, 1986).

Self-Regulated Learning (SRL) theory, an extension of SCT, concerns the means by which students regulate and monitor their own learning processes (Zimmerman, 2002). Selfregulation can be defined as a set of self-directed processes that enable learners to convert cognitive capacities into academic skills and outcomes (Zimmerman, 2002). Self-regulated learners can systematically work towards their goals, because they can activate cognitions, behaviours and affects to this end (Schunk \& Zimmerman, 1994).

Self-efficacy, (SE) an individual's beliefs about their capabilities for learning or performing actions (Bandura, 1986), plays a key role in self-regulation and it affects the choices individuals make (Pajares, 1996; Schunk \& Pajares, 2009) and achievement behaviour (Zito, Adkins, Gavins, Harris \& Graham, 2006). Sources of SE are performance accomplishments, vicarious experiences or observation, social persuasion and physiological states (Bandura, 1997). Learning tasks and content within the secondary school Social Studies environment have an impact on self-efficacy and therefore can help or hinder motivation for further action in this, and wider arenas. The SRSD model is designed to address self-regulation and, in this study, argument writing skills.

\section{SRSD Instruction}

SRSD instruction has three key objectives: (1) to help students develop the necessary higher level cognitive processes involved in academic performance; (2) to support the development of self-regulation strategies for monitoring and managing academic performance; and (3) to encourage positive dispositions towards learning and towards themselves as learners 
(Zito et al., 2006). SRSD is a model for teaching strategies. It is designed to address learners' attitudes and beliefs about self-efficacy and motivation, as well as the targeted process itself, in this case writing. The model emerged from the field of emotional and behavioural learning disorders (EBLD) over 30 years ago (Harris, Graham, Mason \& Friedlander, 2008), and a large body of evidence now supports the effectiveness of the approach, not only for students with EBLD, but also for the general student population (Graham \& Perin, 2007). SRSD with argument writing has been shown to be effective with typically achieving and proficient adolescent students (De La Paz \& Graham, 2002; De La Paz 2005; De La Paz \& Felton, 2010; De La Paz, Felton, Monte-Sano, Croninger, Jackson, Deogracias, Hoffman, 2014; Washburn, Sielaff \& Golden, 2016), as well as students with EBLD, which demonstrates its generalisability.

SRSD consists of six recursive stages of instruction (Develop and Activate Background Knowledge, Discuss It, Model It, Memorise It, Support It, and Independent Performance). It is designed to be flexible, such that the stages can be re-sequenced to target the needs of the students and teacher. Notably, the progression through the stages is not time based, rather it is criterion based, hence the recursive nature of the project. The process is collaborative, between teacher and student(s), and between students, with the goals being to develop writing, content knowledge and self-regulation strategies (Zito et al., 2006).

\section{Argument Writing}

Argumentation, the act or process of reasoning, is a generic skill useful in many subject areas, and central to Social Studies. Essentially, it is the process of making a claim, supporting the claim with relevant evidence, and explaining how the evidence supports the claim. Advanced argumentation includes the recognition of, and addressing of, counterclaims (De La Paz et al., 2014). Conversational argumentation involves the use verbalisation, ideation (i.e., the formation of concepts), and self-regulation. Written argumentation additionally requires skills in transcription, the process by which symbols are created on a page, and self-regulation, the ability to monitor and control one's behaviour (Pajares, Johnson \& Usher, 2007). An argument essay will contain an introduction, an ending, and several paragraphs, each comprising a clear statement, evidence, and explanation linking the two. A well-developed argument essay will contain linking words and counter-arguments. Thus, written argumentation involves a complex set of knowledge and skills. 


\section{Writing Self Efficacy and Writing Self-Regulation}

Self-efficacy is the belief in one's capacity to execute behaviours necessary to produce specific performance attainments (Bandura, 1986). Argument writing can be emotive for some students and can demand substantial amounts of effort (Pajares, Johnson \& Usher, 2007). How learners feel about the process and outcome can influence self-efficacy for argument writing. The beliefs that learners hold about themselves as writers, and learners, are critical elements in the process, in that they affect the degree to which the learners can exercise control over their thoughts, feelings and actions (Pajares, 2003). SRSD is designed to influence those self-beliefs, which are so critical to success in school.

Self-efficacy can influence the degree of effort and persistence expended, and task choice (Schunk \& Zimmerman, 1997). Self-efficacy is influenced by four factors: past performance, vicarious experience, social persuasion, and physiological factors (Bandura, 1986). SRSD addresses these four sources of self-efficacy.

Firstly, vicarious experience is developed through the stages 1-3 of the SRSD method: develop and activate background knowledge; discuss it; and model it. Secondly, social persuasion develops through stages 2 and 5: discussion and support, for example the use of group developed self-statements. Thirdly, past performance is used through the comparison of work across time, using graphs of individual work, rather than peer comparison. Physiological feedback is consequent on the prior three factors. So, affective states are of central concern to the SRSD method, as is explicit, systematic and scaffolded instruction. SRSD, using discussion, mnemonics, graphs, and self-statements, has been shown to improve self-regulation.

Self-regulation in writing can be defined as self-initiated thoughts, feelings and actions that writers use to achieve writing goals (Zimmerman \& Risemberg, 1997). Self-regulation gains have been shown to positively affect writers' self-efficacy, motivation and intrinsic interest in writing (Zimmerman \& Kitsantas, 1999). The SRSD strategies are gradually released, and selfregulation is encouraged by activating learners' prior knowledge and discussing the steps towards skill mastery. This includes goal setting, the use and memorisation of mnemonics and self-statements, and support to practice the argument writing process so that students are able to apply these skills independently. They are then self-regulated learners who use self-generated thoughts and behaviours that are systematically oriented toward the attainment of their goals (Zimmerman \& Shunk, 2001). The evidence base shows that the SRSD method supports the strengthening of these thoughts and behaviours (Bruning \& Kauffman, 2015). 


\section{Knowledge of Writing}

Skilled writing is a complex activity that involves declarative, procedural, and conditional knowledge about the writing process, genre and context (McKeown et al., 2016). Declarative knowledge about writing refers to knowledge about specific writing processes. Procedural knowledge about writing refers to knowledge about how use or apply writing processes. Conditional knowledge of writing refers to knowing when and why certain processes should be used. Students need awareness of these three kinds of knowledge for writing strategies. In the classroom, opportunities to develop this knowledge through practice often compete for time with content learning. Given time constraints within schools, some content may necessarily be sacrificed to enable writing practice, and the New Zealand curriculum and assessment framework has been designed to accommodate this shift (Ministry of Education, 2007).

The recursive, criterion based SRSD method is designed to provide sufficient opportunities to practice the process, observe successful modelling, and receive considered feedback in a timely fashion, within a supportive learning environment. Modelling, discussion, goal setting and progress monitoring are an integral part of the SRSD process. These, and opportunities to practise, can be considered the basics for the development of writing knowledge. Further, the flexible nature of the SRSD model means that teachers can adapt lesson materials to suit their learning content (De La Paz et. al., 2014).

A recent meta-analysis (Santangelo, Harris \& Graham, 2016) examined 38 studies of cognitive strategy instruction interventions, 25 of which deployed the SRSD model (Graham \& Harris, 2005; Harris et al., 2009), and SRSD has been shown to produce significantly greater effects than non-SRSD interventions. The authors (Santangelo, Harris \& Graham, 2016) point to a paucity of research on writing development over time, and the use of self-regulation and writing, as well as gaps across the learning levels: most of the research has examined primary and tertiary level learners.

The basis for strategy focused writing instruction lies in the theories that position selfregulation as central to learning the craft of writing (Schunk \& Zimmerman, 1997; Zimmerman and Reisemberg, 1997). Learners' skill acquisition is conceptualised as multilevel, comprising: observation, emulation, self-control and self- regulation. Self- regulation theory stresses the role of social support, self-motivation and goal-directed practice (Zimmerman \& Kitsantas, 1997). Social cognitive theory (Bandura, 1986) posits a distinction between self-control and selfregulation that implies a focus on strategic processes (process goals) rather than outcomes (product goals). This is beneficial to novice writers who are beginning independent practice. The 
novice learner benefits from sequenced steps towards writing skill acquisition (Graham \& Harris, 1989, 1994) given that writing is a problem-solving process requiring thinking and reasoning (Bereiter, Burtis \& Scardimalia, 1988). A focus on process rather than product results in a reduction in metacognitive demands that addresses the difficulty that novice writers experience: the dilemma of where to focus their cognitive resources appropriately, and at which point in time (Bereiter, Burtis \& Scardimalia, 1988). The SRSD method encourages a process focus.

It has been found that younger students are constrained in writing tasks by transcription (hand writing and spelling) abilities. As students mature and participate in school instruction, these skills theoretically become automatised, and this long term cumulative process may have a positive effect of self-regulation skills. However, when automisation does not keep pace with level expectations or norms, self-regulation skills may be negatively affected. In these instances, it has been found that transcription competes with self-regulation in writing (Limpo \& Alves, 2013). This finding supports the review of Graham and Harris (2000) which found that writing development is dependent on automisation of transcription, and relies on high levels of selfregulation.

\section{Socio-Cultural Theory and SRSD}

In this study, the mnemonics POW + TREE (Harris, Graham \& Mason, 2002) are adjusted and expanded to become RAP + POW + TREE + FAIL (see Appendix 1). Source analysis is supported with the mnemonic RAP - Read, Ask questions, and Put in your own words (Harris et. al., 2008). Paragraph writing skill is developed using POW - Pick an Idea, Organise your notes, and Write and say more, and TREE - Topic sentence, Reason, Evidence, Evaluative statement. Finally FAIL - From Attempts I Learn - is employed to address affective states within the diverse class. Further, the SRSD method is applied to argument writing in a classroom operating on the philosophy espoused in Angus Macfarlane's Educultural Wheel (MacFarlane, Glynn, Cavanagh \& Bateman, 2007: see Appendix 2). This model positions the 'pulse of the room' Pumanawatanga as an influence on student self-efficacy, self-regulation and knowledge. This environmental approach is designed to address the cross-cultural complexities inherent in the diverse classroom (Bishop \& Berryman, 2006). The culturally responsive approach positively influences affective dispositions towards learning, and so strengthens the SRSD approach. An SRSD intervention is embedded within two units of work: 'What's the 
Real Cost?'- the economic effects of the global fashion industry; 'Why does Good Government Matter?'- a comparative study of the New Zealand Government System, and the current civil war in Syria. These contexts are relevant to the students' lived experiences. The writing tasks are framed as purposeful in the wider learning or community context as this is potentially helpful to self-efficacy and therefore motivation for writing (Bruning \& Kauffman, 2016).

Given that collaborative writing, incorporating group-based pre-writing activities, is shown to be an effective strategy for teaching adolescents (Graham \& Perin, 2007), group learning in source analysis and paragraph construction are integrated into the SRSD method. Zimmerman and Risemberg's (1997) model of writing, incorporating environmental, behavioural and covert or personal forms, combined with Macfarlane's Educultural Wheel (MacFarlane et.al., 2007) are helpful models underpinning this interpretation and implementation of SRSD in an academically and culturally diverse Social Studies classroom.

The explicit goal of the SRSD process is to develop writers who have mastered the "higher level processes involved in composing, developed autonomous, reflective, self-regulated use of writing strategies, and formed positive attitudes about writing, and themselves as writers" (Graham \& Harris, 1993). It is important to build self-efficacy when students do challenging domain-related tasks in less than ideal motivational contexts (Pajares, 2001). Writing as one such domain (Bruning, Dempsey, Kauffman, Zumbrunn \& McKim, 2013), and adolescence is a time of personal turmoil (Graham \& Perin, 2007). Students bring to the high school classroom the attitudes and beliefs developed from their prior learning experiences. It is by no means the majority who arrive positively disposed to the task of writing.

The beliefs and expertise of teachers are key to evidence-based practice implementation. It is unusual to qualify as a teacher with any specific training in writing instruction, or in managing EBLD. Therefore, the strong evidence base underpinning SRSD as an effective strategy for the broad range of students in the general classroom is important when teaching students from increasingly diverse backgrounds. It addresses the professionally and psychologically challenging approach of 'teaching to the middle' - the typical strategy for teacher training. Funding and support are yet to keep pace with increasing classroom diversity. Meanwhile, the outliers on either end of the learning needs spectrum grow increasingly remote from each other, and indeed from the cognitive, administrative and pedagogical capacities of this full-time teacher. An evidence-based approach that benefits all students is a useful tool for the increasingly time constrained teacher. 


\section{Literature Review}

A series of searches was done across 8 months, from February 2016 to September 2016, to identify gaps in the research, and work already undertaken within secondary school, middle school or high school classes, on writing in social studies, and SRSD. Studies that examined opinion or argument writing within whole class (Tier 1) settings were sought. The inclusion criteria were middle, high or secondary school, Tier 1, motivation, SRSD, writing, opinion, or argument writing, or writing instruction. The searches were limited to journal articles published between 1986 and September 2016. A small number of studies were located, and these supported the efficacy of the SRSD method applied to writing instruction. Further research was then undertaken on the degree to which classroom interactions influence student engagement with writing in general. Studies of teacher expectations and approaches to writing instruction were also sought, to inform the teacher led intervention. Searches were conducted with Te Waharoa, Primo, and Science Direct using the terms 'SRSD and Writing'; 'Secondary + Social Studies + Writing'; 'Writing + SRSD + Adolescents'; '(SRSD AND "high school") OR "secondary school"'; 'secondary “writing skill” New Zealand'; 'SRSD writing New Zealand'. Searches of ERIC, PROQUEST Educational, PROQUEST Psychology, Psych Info were made using the terms SRSD, Secondary or Middle School and Writing. A further search of Te Waharoa and Primo was done using the terms 'Self-Regulation and Writing', and again using 'Self-Efficacy and Writing'. The British Journal of Educational Psychology was searched using the terms 'SRSD and Writing'. The bibliography of Zumbrunn, Marrs and Mewborn (2015) was also searched, as were the references contained within the Handbook of Writing Research, 2nd ed. (MacArthur, Graham, Fitzgerald 2016). Discussions with colleagues elicited further readings. The items retrieved were then culled to eliminate studies that focussed on participants defined as having Emotional and Behavioural Learning Disorders (EBLD), English as a Second Language learners, Adult Literacy Learners, and Elementary School learners. Individual (Tier3), small group (Tier 2) were also eliminated.

The review first discusses the findings of Tier 1studies of SRSD and opinion or argument writing. Then research that examines the provision of writing opportunity, and teacher approaches to writing, student diversity, and learning environment is examined. Next, studies that examine the student perspective are discussed, as is relevant New Zealand research. Finally, research with a Social Studies focus, and the SRSD method are discussed. The literature review table reflects this approach. 
Wong, Hoskyn, Jai, Ellis \& Watson, (2008) conducted an early Tier 1 SRSD and opinion writing intervention, with two general education Canadian middle school classes. Students who received the SRSD instruction, on average, produced work of greater clarity and organisation, than the students who received standard instruction. Goal setting was identified as a key motivator for the majority of the students in the SRSD condition. The researchers noted that the treatment had high social validity with both teachers and students. Interestingly, the study also noted that while the students in the SRSD intervention progressed on average, the sample did not progress at the same rate of change, or along the same change trajectory.

In another more recent study, Limpo and Alves (2013) examined the effects of planning and sentence combining strategies on opinion writing and self-efficacy for writing for 5 th and 6th grade students in Portugal. The researchers found that the SRSD intervention failed to increase students' self-efficacy. The authors suggested this could be related to over-estimated writing efficacy at pre-test. Students who received strategy instruction showed improvements in the quality and length of their opinion essays compared to students who received the standard writing instruction, that was whole class grammar instruction, and independent text production. Moderate correlations were found between self-efficacy and writing quality for both planning and sentence combining. It is suggested that self-monitoring may have adjusted student perception to be more realistic, and in line with their current performance, and this may account for the lack of shift in students' self-efficacy for writing. The authors noted that practice of the planning strategy alone improved the completeness and coherence of the students' opinion essays (p. 338).

Further work by Limpo and Alves (2013a) tested students' implicit theories of writing, and whether these beliefs influenced SRSD writing instruction. Again, as expected, SRSD planning instruction produced longer and better opinion essays than those produced in the comparison group. It is thought that the plan acts as an external memory, storing ideas, in turn freeing up the writers to concentrate on other key writing processes. The researchers found that the more that students thought of writing as a potentially strengthening skill, the more the quality of their text improved.

Another study (Fidalgo, Torrance, Rijlaarsdam, van Den Berg, \& Alvarez, 2015) tested the effectiveness of individual elements within SRSD instruction as it applies to writing: declarative teaching of writing strategies supported by mnemonics and graphic organisers, student observation of mastery modelling of these strategies, pair or group writing practice, and solo performance. While these are understood to be collectively effective in developing writing skills, these researchers aimed to establish the relative value of each of these components. The 
study found that observing and reflecting on a mastery model was sufficient to give large gains in writing improvement within the female adolescent population. Resequencing the SRSD approach addressed the issue of the 'double challenge' of recalling and implementing strategies while concurrently undertaking the demanding writing task. By starting the intervention with observation, discussion, and practice, then, in latter sessions, introducing direct (declarative) instruction with mnemonics, and peer feedback, an opportunity for less able writers to gain ease with the writing process was generated. In this study, pair or group writing practice, and peer discussion of effective writing processes also sustained improved writing performance.

Washburn, Sielaff and Golden (2016) used SRSD instruction to focus on argument writing that was integrated with course content. Students were given SRSD instruction, the PEA (Point, Evidence, Analysis) mnemonic, along with a specific historical analysis mnemonic. These students wrote longer responses and had more improved writing quality than the comparison group, who had no explicit writing instruction or teacher modelling, but otherwise shared the same course content. The urban middle school sample showed statistically significant differences in argument essay products between the strategy and control groups. The analysis is notable in that it demonstrates the general applicability of the SRSD method: gains in writing production were made by students of the highest proficiency, as well as those who struggle academically.

This work builds on that of De La Paz et al. (2014), in that it develops disciplinary specific, yet transferable, skills and uses primary documents or teacher devised products to do so. Further, both studies embedded the direct strategy instruction within the programme content. Writing skill learning, and content learning were interwoven, so that the Social Studies teachers deliberately developed writing skill through content learning.

This approach addresses the contention of Applebee and Langer (2011), that teachers do not provide enough opportunities for students to develop their writing capacity. This observation was developed from classroom visits across 20 middle and high schools, interviews with teachers and students, and surveys of more teachers. This observation is supported by Capizzi, Harris, Herbert and Morphy (2014) and Ray, Graham, Houston and Harris (2016). These researchers have found from surveys of middle school teachers in the US that writing opportunities in the classroom remain limited across different disciplines. Further, there is a wide variation in the practices teachers apply to writing learning across disciplines. Another study (Wilcox, 2015) identified differences in access to writing opportunities. Where writing opportunities were presented, Wilcox (2015, p. 216) stated that "higher and lower tracked 
students experienced disciplinary writing in distinct ways in terms of the expectations for the kinds and complexity of writing and the importance placed on writing in content learning".

The consequence of this is that students whose writing skill has fallen below their grade level, may then receive insufficient opportunities to improve, further impacting on selfregulatory capacity and writing skill. At the very least, this finding points to 'lower track maintenance' on the part of the teachers. Wilcox quotes a pithy unnamed district administrator who pinpoints the scope of the problem: "Nine out of ten of the teachers would hammer identifying supporting details. That's not the root of the problem: the teachers of Social Studies would say they [students] didn't know the facts, but in fact students didn't have the skills to incorporate them" (p. 252).

Therein lies the problem. Without the skills necessary to present factual knowledge, students will struggle to develop an agentic approach to writing, which is the capacity to move beyond the presentation of "what is already known" to what a student writer has to say about it (Jeffery \& Wilcox, 2014, p. 1113). This “opportunity gap" has also been identified in New Zealand, where deficit thinking on the part of teachers was identified as a major impediment to educational achievement for Māori students; low expectations on the part of teachers result in limited learning opportunities for the students. (Bishop, Berryman, Cavanaugh \& Teddy, 2009, p. 740).

Creating time for course content to enable fair and equitable skill improvement is suggested as possible through a tikanga Maori (culturally responsive New Zealand indigenous) approach such as the Educultual Wheel (Macfarlane et.al.2007) that positions learning as reciprocal between teacher and student. In this model teachers are encouraged to build relationships personally, more than professionally, with students, and to position themselves as responsible for the cultural and academic safety of all students (Macfarlane, Glynn, Cavanagh \& Bateman, 2007). Such an environment supports all parties in the writing learning process to become agentic writers. It enables a collective and collaborative approach to learning which in turn, assists in the affective process within the act of writing (Pajares, Johnson \& Usher, 2007). An environment (the room, the furniture placement, the teacher, the students) shapes the affective dispositions of the students towards learning, and the way the environment is interpreted by each learner is critical (Bishop, \& Berryman, 2006, Macfarlane et.al., 2007). In a socio-economically and culturally diverse room, the responsibility for the affective and cognitive dispositions of the students is a significant challenge.

One of the factors that influences cognitive and affective dispositions is feedback from the teacher. It has been found that student perceptions of feedback, in the broader environmental 
sense (Bishop \& Berryman) and in regard to writing (Zumbrunn Marrs and Mewborn, 2015) play an influential role on student motivation and self-regulation for learning and writing.

The work of Zumbrunn and her colleagues (2015) addresses the critical role writing feedback perception has on adolescent student writing motivation and self-regulation beliefs. While some students experience strong positive affective responses to teacher feedback, other students perceive feedback sufficiently negatively to avoid it altogether. The adolescent emotional experience is turbulent, and the researchers point out that teachers should be mindful of the adolescent tendency to view feedback as pertaining to them, more than to their work. Further, the level of openness to receiving feedback is related to students' beliefs about their ability to accomplish writing tasks. The more the students feel the environment reflects, respects, and supports them, the greater willingness to engage in the challenges of writing. (Bishop \& Berryman, 2006). The Educultural Wheel is an instrument to support the teacher to meet diverse learning needs despite time and cognitive constraints (Macfarlane et.al, 2007). Similarly, the SRSD model, through its powerful evidence base, enables the teacher to recognise the efficacy of the learning design affectively and cognitively (Harris et.al, 2008).

Using SRSD and the classroom environment to support argument writing, Felton and Herko (2004) too, cite the climate in the room as a useful tool in shifting adolescent attitudes to argument writing. When teachers enable argument as a natural part of classroom discourse, the natural adolescent aptitude for verbal argumentation is tapped into. This supports ideation and vocabulary building (transcription), key components of the writing process. Further, the social engagement in argument discourse supports self-regulation (Felton \& Herko, 2004), when respect is the emotional baseline in the room (Bishop \& Berryman, 2006, Macfarlane et.al.,2007).

In the New Zealand context, qualitative interviews with 2 classes of high school students indicate that engagement with writing tasks is affected by interest in the topic and the perceived relevance of the learning (Hawthorn, 2008). Further, the interviews indicated that skilled writers prefer choice and control, whereas reluctant writers tend to seek support from the teacher. In this study, perceptions of teacher feedback were also noted as affecting reluctant female adolescent writers. Writer point of view is more strongly held, and therefore potentially developed, when learning contexts are perceived as relevant to students (MoE, 2007, Hawthorn, 2008).

Access to appropriately challenging learning opportunities has similarly surfaced as an issue in the work of Jeffery and Wilcox (2014). The qualitative discourse analysis of interviews with high and low tracked students in urban US high schools indicated that both high and low achieving students were favourably disposed to more opportunities for extended writing and for 
written argument involving writer point of view, across core subject disciplines (Jeffery and Wilcox, 2014). The research indicated that lower tracked students were disadvantaged in their skill development by a lack of access to extended argument writing tasks.

De La Paz and her colleagues $(2005,2010,2014)$ argue that teacher decisions on the source material offered to students also influences writing improvement in Social Studies classes. When students worked with primary sources, and received SRSD instruction in argument writing, the students addressed counter argument within their essays at 3 times the rate of the control group, who used text books for source material and had no SRSD argument writing instruction (De La Paz \& Felton, 2010).

Teachers are effective when they can transfer underlying concepts and skills across learning contexts (MoE, 2007). De La Paz $(2005,2002)$ noted that a factor in intervention effectiveness, was teacher approach to the process, and teacher grasp of the underlying processes. Nystrand and Graff (2001) through classroom observations found that a teacher focus on prescriptive outcomes potentially constrains the writing process, but teacher modelling of source analysis was effective, supporting the SRSD model.

What teachers think they are doing, and what they are actually doing in the classroom are not necessarily the same things. While Social Studies is recognised as a text rich subject, exposure to appropriately challenging learning opportunities, (reading, writing) is not the norm. For example, the opportunities to engage with complex text and demanding writing tasks were less than expected by researchers in reanalysis of narrative notes from classroom observations of five US high schools; in 20.5 of 34 observed hours of Social Studies instruction, students were not engaged with text at all. Only rarely were students expected to write more than a paragraph. The predominant teaching modes were lecture, discussion and Q\&A (Zigmond, 2007). Limited opportunities to observe and practice writing skills will impede students improved self-efficacy for writing in Social Studies, as they progress through secondary school. The New Zealand Curriculum is broad in the scope it allows teachers (Ministry of Education, 2007), even so, Zigmond's research reflects the experience of this teacher researcher, and indeed that of a decade of her charges.

The literature demonstrates that increased opportunities for mastery experiences, through practice, and enabling recognition of skilful writing, via observation, are valuable steps in learning how to write argument based essays. Argumentation, the act or process of reasoning, is a generic skill useful in many subject areas, and central to Social Studies. Essentially it is the process of making a claim, supporting the claim with relevant evidence, and explaining how the 
evidence supports the claim. Advanced argumentation includes the recognition of, and addressing of counterclaims (De La Paz et.al., 2014). While conversational argumentation takes verbalisation, ideation and self-regulation, argument writing requires skills in transcription, the process by which symbols are created on a page; ideation, the formation of concepts; and selfregulation, the ability to monitor and control our behaviour (Pajares, Johnson \& Usher, 2007). An argument essay contains several paragraphs, each comprising a clear statement, evidence, and explanation linking the two. These are supported with a thesis statement and a conclusion. A well-developed argument uses linking words between paragraphs and contains counterargument. To construct an argument in writing, a student must draw on skills in transcription, ideation, and self-regulation, (Pajares, Johnson \& Usher, 2007).

The six-staged SRSD model: Develop Background Knowledge, Discuss It, Model It, Memorize It, Support It, and Independent Performance is designed so that the steps within these skills can be scaffolded, with mnemonics and writing supports, and practiced so that mastery is observed through graphed feedback, which in turn supports self-regulation. (Harris et.al, 2008). Under this model, students can gauge their level of success against criteria, and set goals for self-improvement. The SRSD method enables a focus on process goals, then outcome goals, helpful to novice writers who tend to focus too hastily on outcome goals (Zimmerman \& Kitsantas, 1999). The recursive nature of the model means teachers and students can move between the stages, enabling flexibility to meet diverse classroom needs. Progress graphing is a somewhat neutral measure, and as such, perhaps addresses the complications inherent in the diverse perceptions students have of writing feedback, (Zumbrunn, Marrs \& Mewborn, 2015). Progress graphing enables the students to see and therefore, feel, their progress not necessarily mediated by the teacher/student relationship. The graphing of individual progress enables the measure of shift against self, rather than peers.

There is a strong evidence base for the effectiveness of the SRSD method applied to writing in Social Studies, (Washburn, Seilaff \& Golden, 2016, De La Paz, Felton, Monte-Sano, Croninger, Jackson, Deogracias Hoffman, 2014, Limpo \& Alves, 2013, De La Paz \& Felton, 2010, Wong, Hoskyn, Jai, Ellis \& Watson, 2008, De La Paz, 2005, Felton \& Herko, 2004, De La Paz \& Graham, 2002,), and a growing body of work detailing practitioner adaptations to the model (Wasburn, Seilaff \& Golden, 2016, Wong, Hoskyn, Jai, Ellis \& Watson, 2008, Herko \& Felton, 2004,). This record has demonstrated the efficacy of the evidence based SRSD method in building argument writing. The SRSD method, with its roots in EBLD learning, and drawing on SCT and Bandura's model of reciprocal interaction, is an evidence based practice for developing argument writing. The literature shows that writing is a complex cognitive act 
generating high demands on working memory, hence writing development advances slowly. Writers form strong impressions of their writing experiences, (Bruning, Dempsey, Kauffmann, McKim, \& Zumbrunn, 2013), and their classroom environments (Bishop \& Berryman, 2006), and these impressions shape their approach. Given that ideation, transcription and self-regulation are integral to the writing process, and are each highly recursive, as is writing itself, extended and deliberate integration of writing practice into the discursive classroom environment and learning plan, seems likely to promote argument writing skills.

Building on the research to date, this study seeks to investigate the effects of SRSD and argument writing instruction combining a sociocultural and cognitive/motivational perspective (Graham \& Perin, 2007). Consideration is given to classroom environment, content material, and feedback processes. Using a modified and extended version of POW + TREE, Harris et.al., 2007) the study examines the relative effectiveness of SRSD on a class of diverse adolescents. 


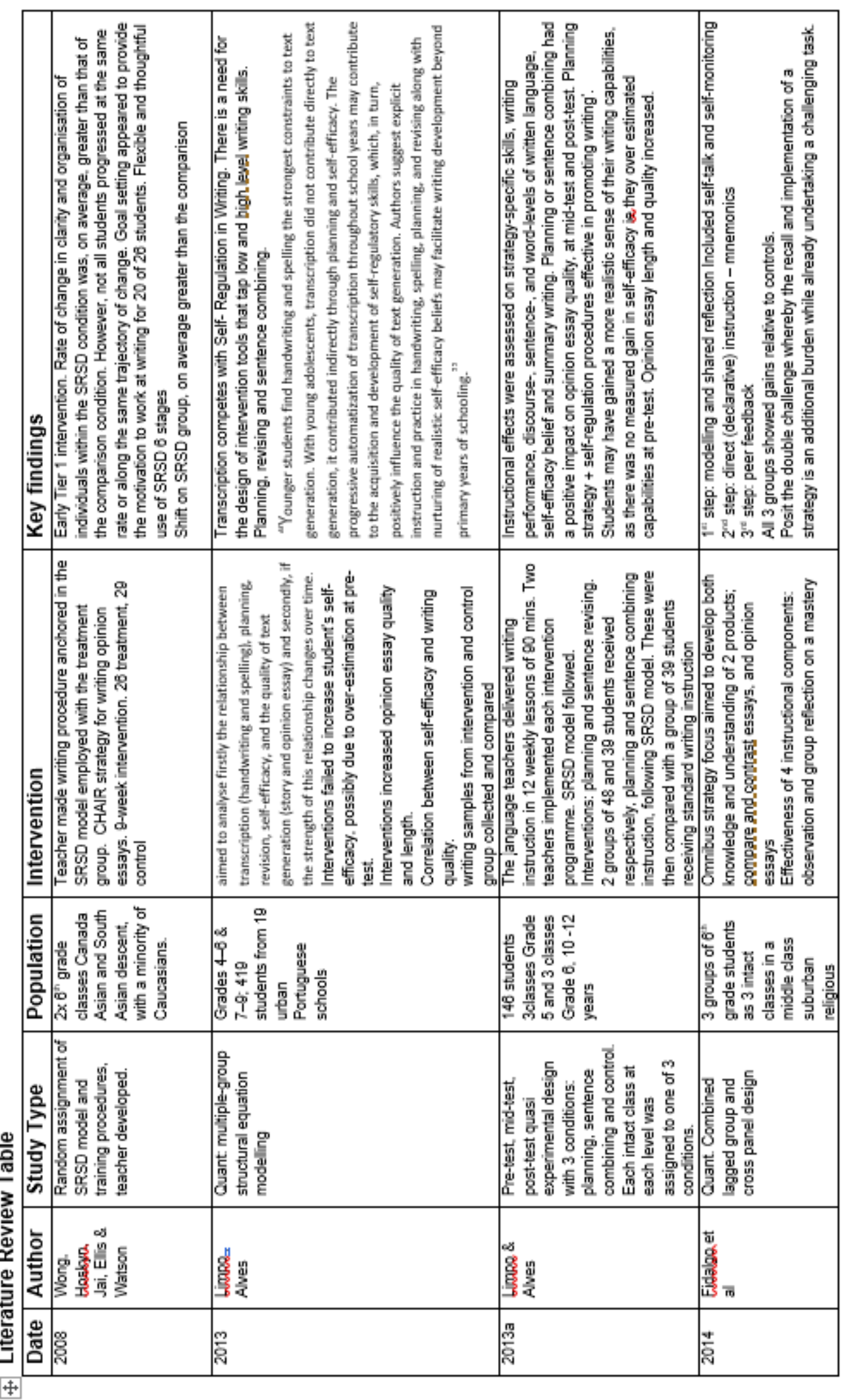




\begin{tabular}{|c|c|c|c|c|c|c|}
\hline & 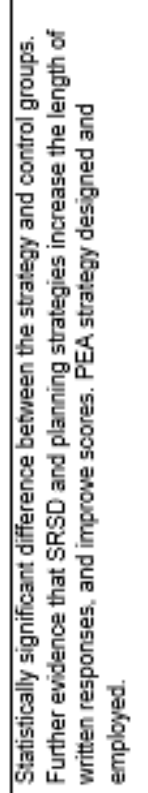 & 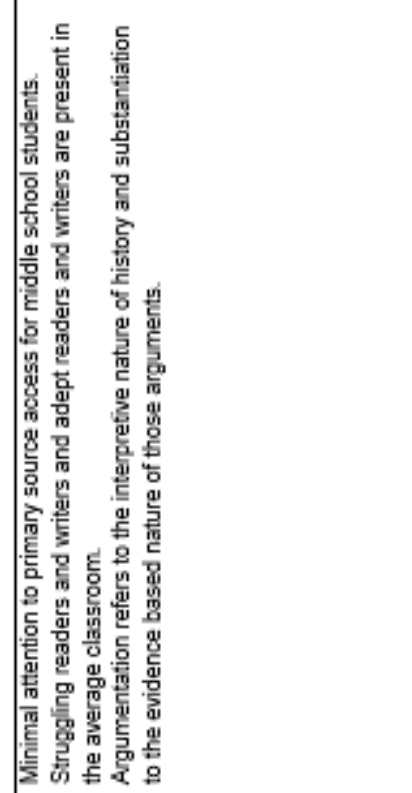 & 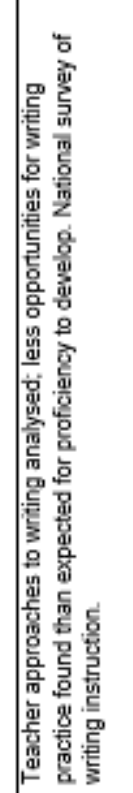 & 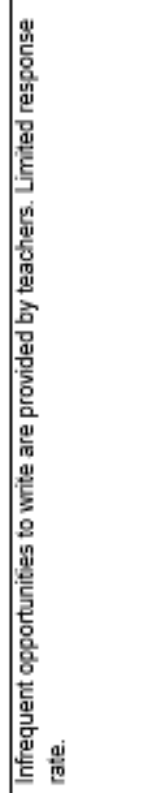 & 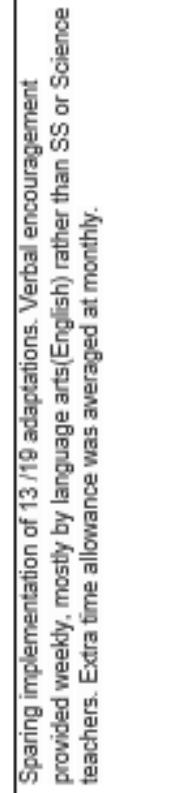 & 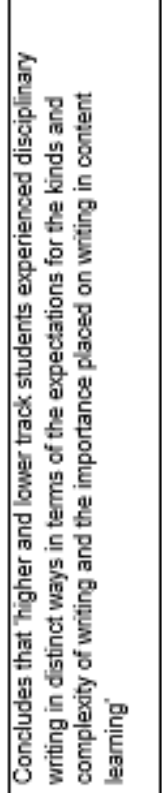 \\
\hline 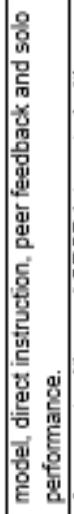 & 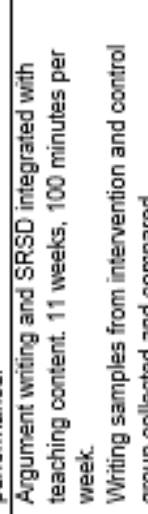 & 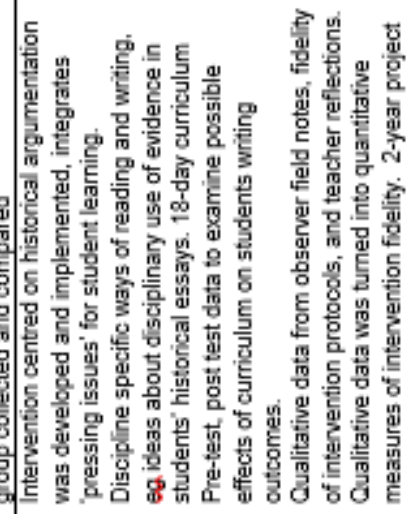 & 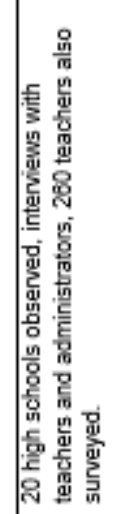 & 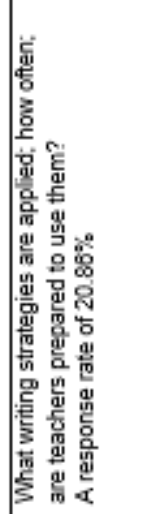 & 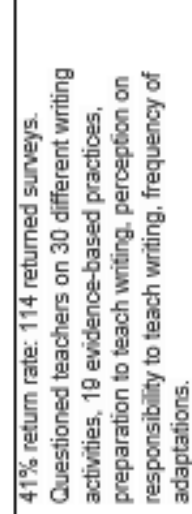 & 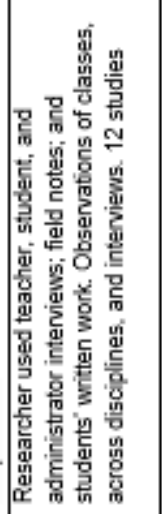 \\
\hline 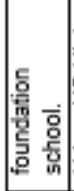 & 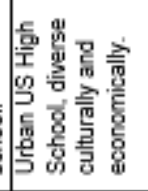 & 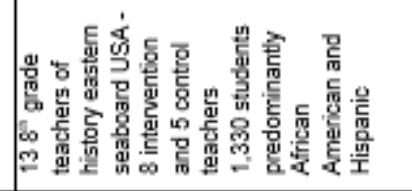 & 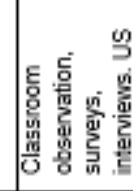 & 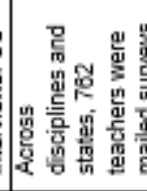 & 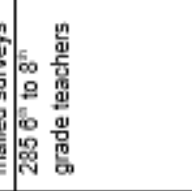 & 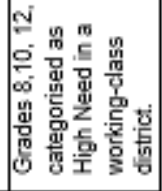 \\
\hline & 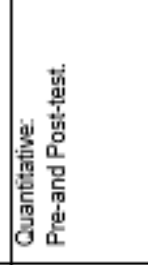 & 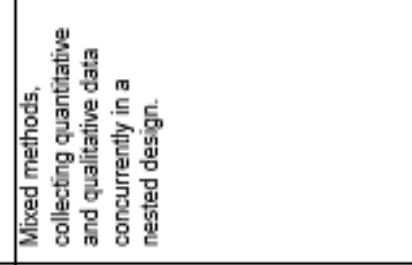 & 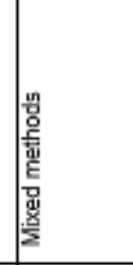 & 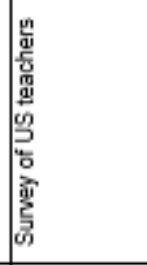 & 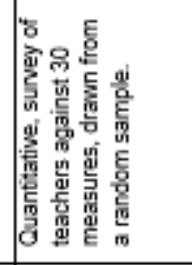 & 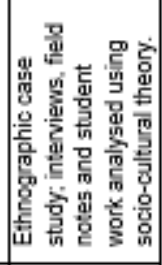 \\
\hline & 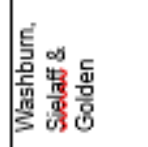 & 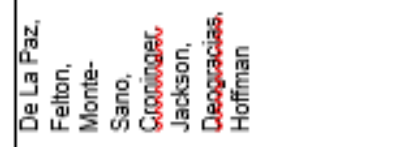 & 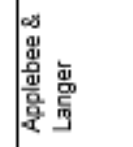 & 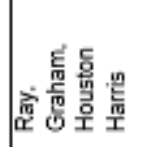 & 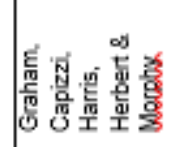 & 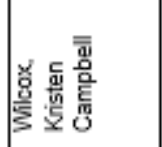 \\
\hline & 商 & 蒿 & 六 & 离 & 兽 & $\sqrt{N}$ \\
\hline
\end{tabular}




\begin{tabular}{|c|c|c|c|c|}
\hline & 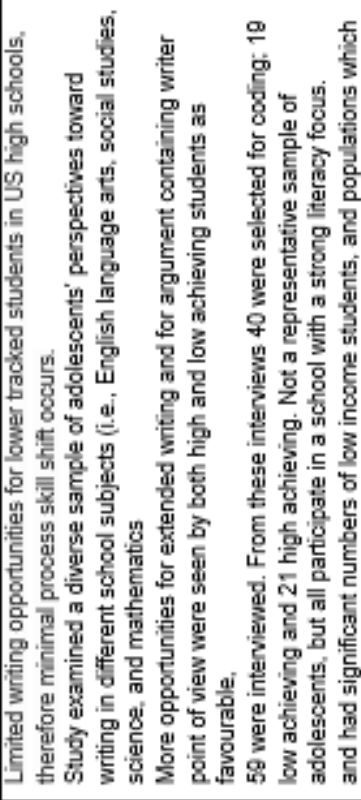 & 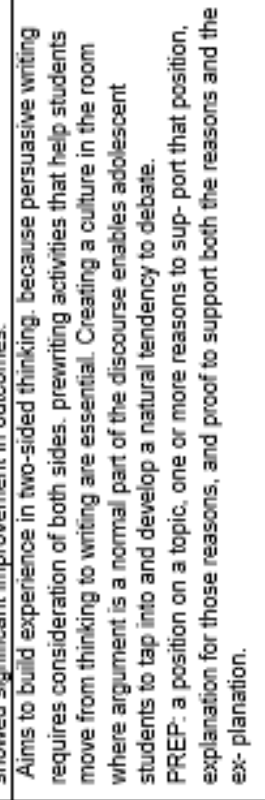 & 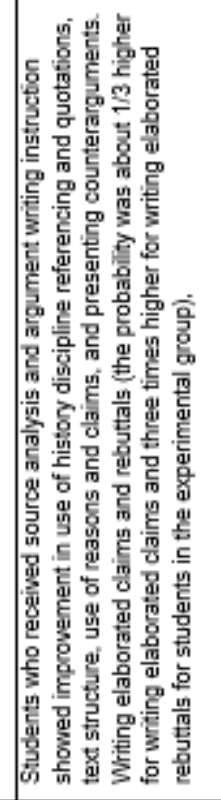 & 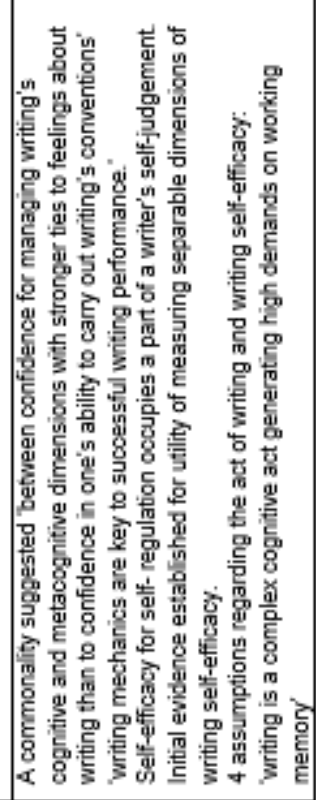 \\
\hline & 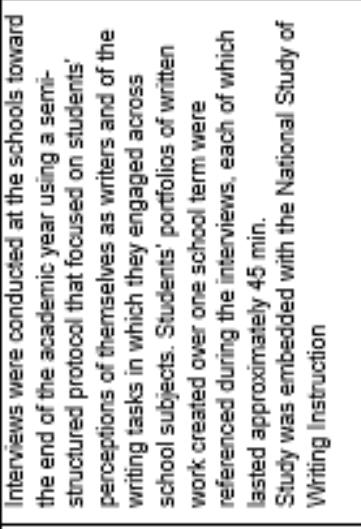 & 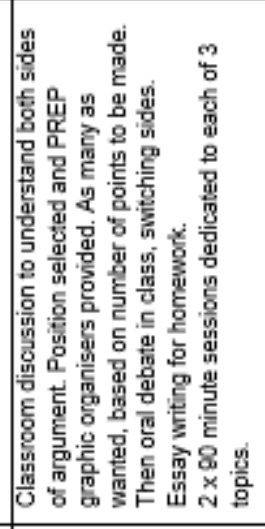 & 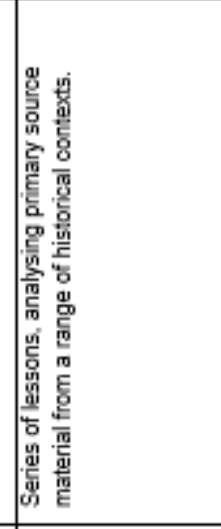 & 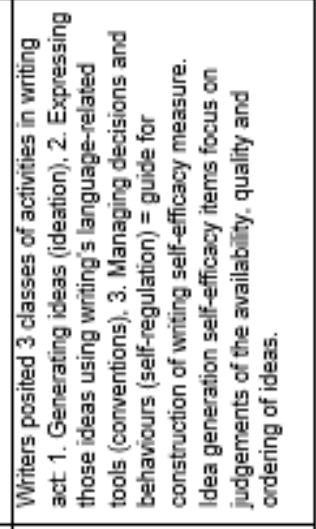 \\
\hline & 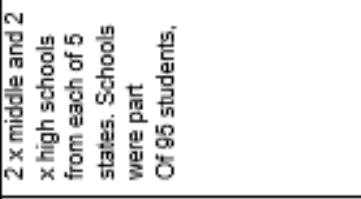 & 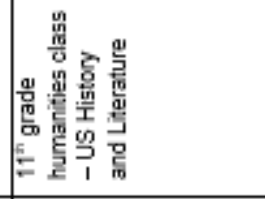 & 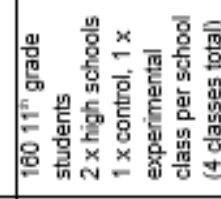 & 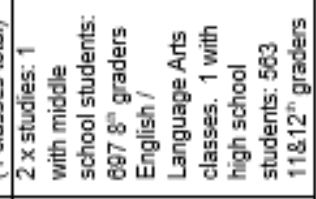 \\
\hline & 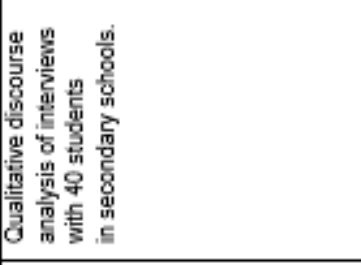 & 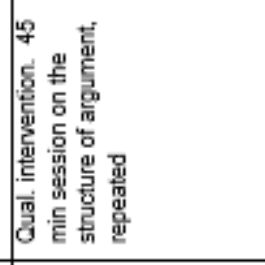 & 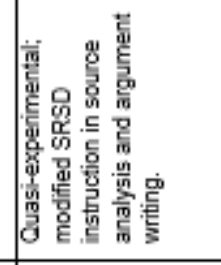 & 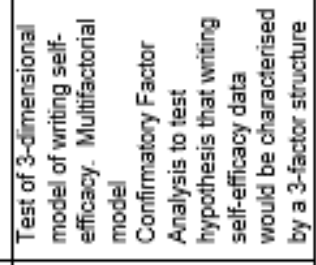 \\
\hline & & $\begin{array}{l}\infty \\
\frac{5}{2} \\
\frac{2}{4} \\
\frac{1}{4}\end{array}$ & 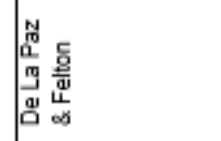 & 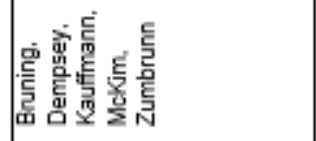 \\
\hline & $\sqrt{2}$ & 唐 & $\sqrt{2}$ & 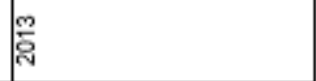 \\
\hline
\end{tabular}




\begin{tabular}{|c|c|c|c|c|c|}
\hline 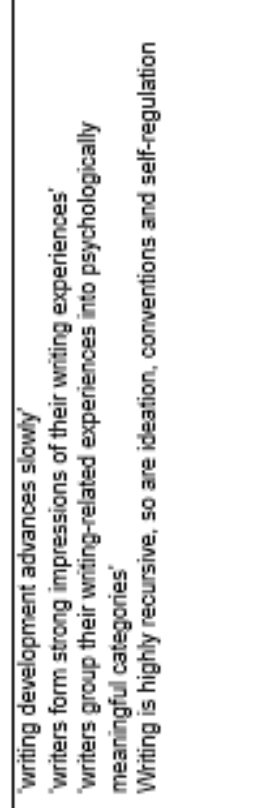 & 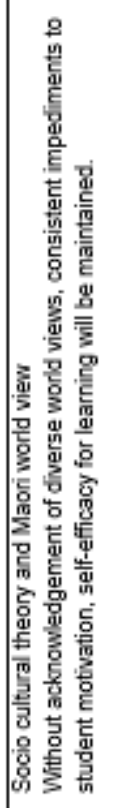 & 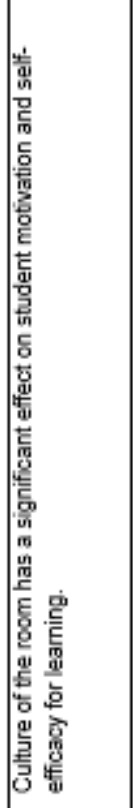 & 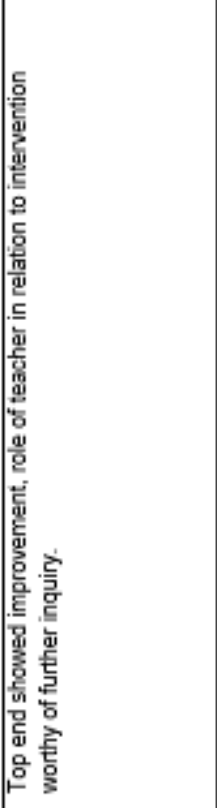 & 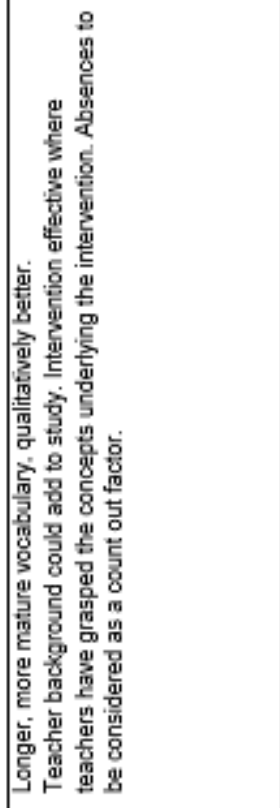 & 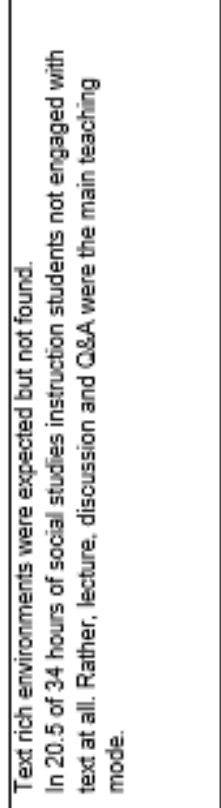 \\
\hline 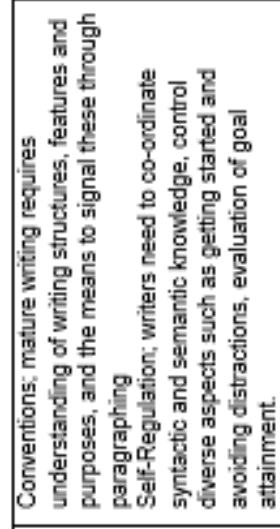 & 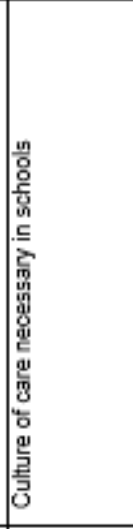 & 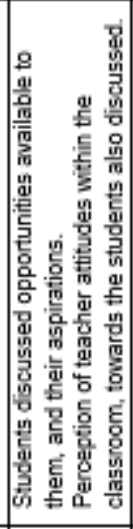 & 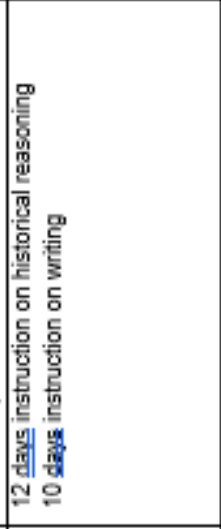 & 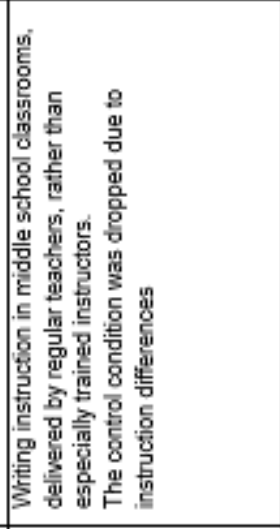 & 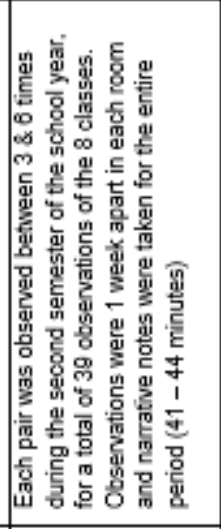 \\
\hline 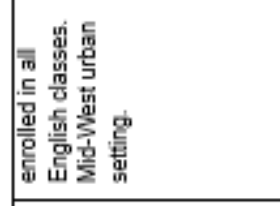 & & 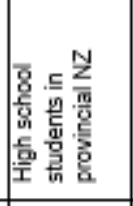 & 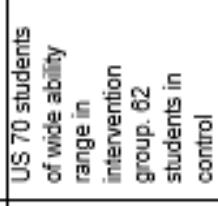 & 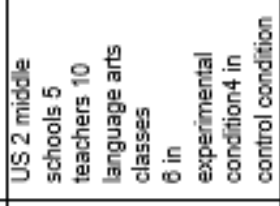 & 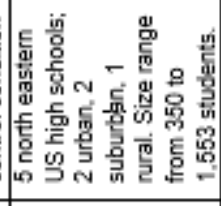 \\
\hline \multirow[t]{3}{*}{ 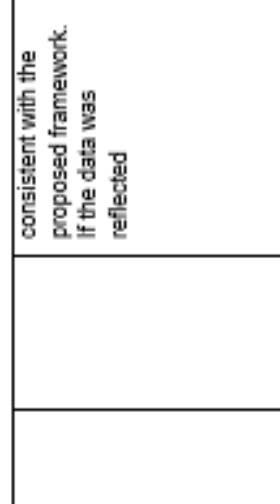 } & 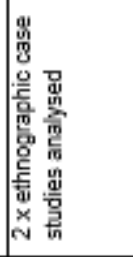 & 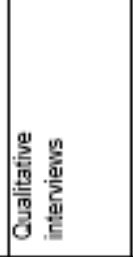 & 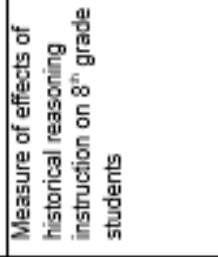 & 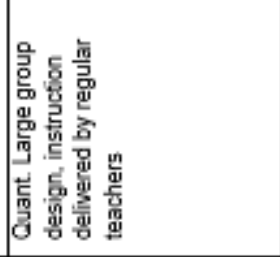 & 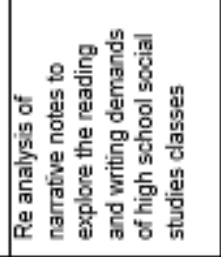 \\
\hline & 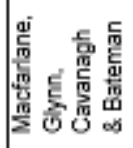 & 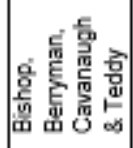 & & 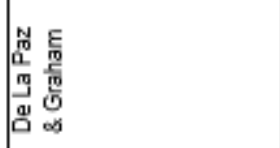 & 雚 \\
\hline & 产 & 苓 & 总 & 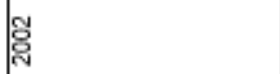 & 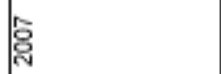 \\
\hline
\end{tabular}




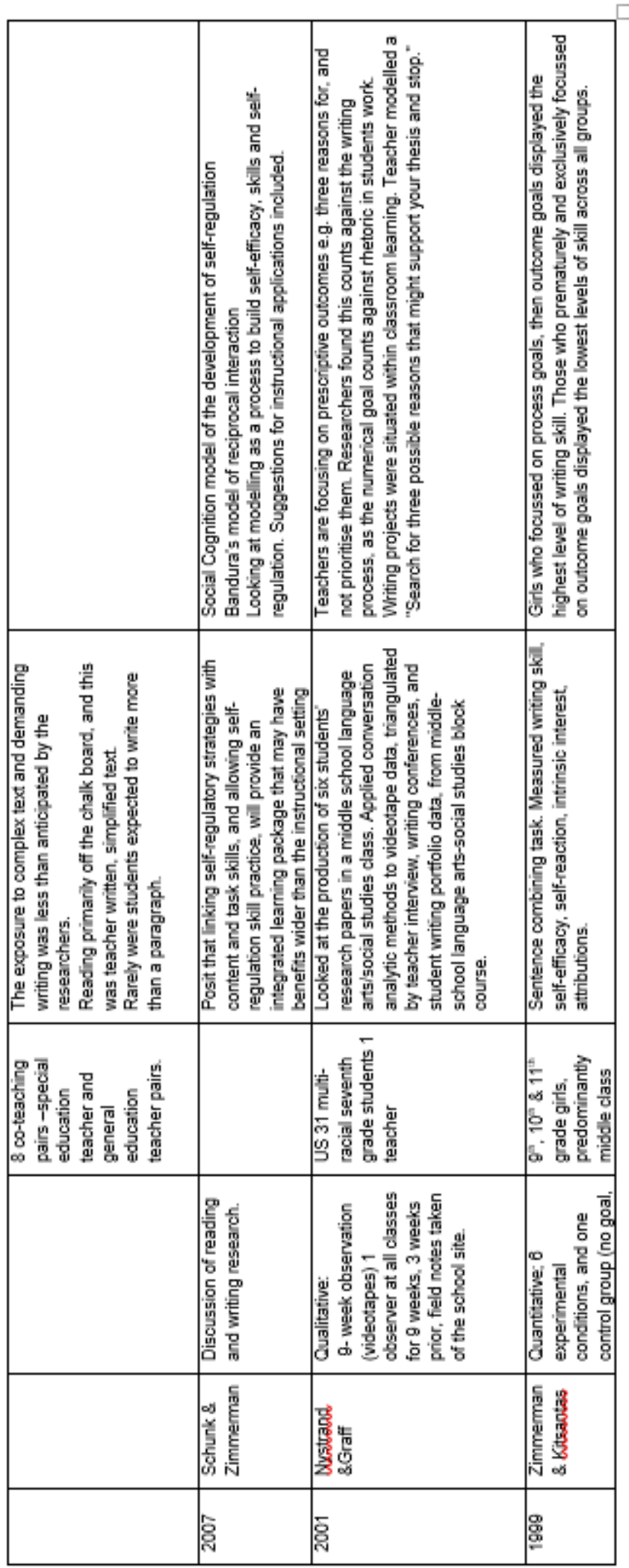




\section{The Present Study}

The purpose of this mixed methods study was to investigate the effect of the classroom teacher applying an SRSD intervention to argument writing in a standard classroom environment. An investigation into the differences in outcomes across the population was undertaken. An explanatory sequential mixed methods design (see Appendix 3) was used because it enabled the examination of both quantitative and qualitative aspects of writing, and it provided a means of adding insight to quantitative findings (Creswell \& Plano Clark, 2011).

In the quantitative phase, self-efficacy for writing and writing self-regulation aptitude, as well as knowledge of writing, were measured through pre- and post-intervention digital questionnaires. Secondly, writing product samples were gathered in the pre-intervention phase, and these were coded and these codes averaged. A comparison was then made with a postintervention writing sample. Based on theory and previous research (Washburn, Seilaff \& Golden, 2016; De La Paz, Felton, Monte-Sano, Croninger, Jackson, Deogracias Hoffman, 2014; Limpo \& Alves, 2013; De La Paz \& Felton, 2010; Wong, Hoskyn, Jai, Ellis \& Watson, 2008), a post-intervention improvement in written argument products was anticipated. This study investigates the reasons for differences in degree of improvement across the sample. In the qualitative phase, a subset of participants was interviewed to gain a richer perspective on the reasons for their relative gains in written argument product development, and changes in self-regulation. Pairs of participants were selectively sampled for interview on the criterion of averaged gains across the variables. Students who made low, medium and high gains were selected for interview. Within-group comparisons and across-group comparisons were made. Both datasets were then integrated to provide a more comprehensive understanding of the possible reasons for differences in the measured effectiveness of this SRSD intervention.

This study differed from the previous research in several ways. Firstly, the relative effectiveness of an SRSD intervention on the argument writing processes and products of students in Social Studies class was explored. Secondly the study was undertaken by the teacher practitioner, with some research assistant support. Thirdly, the strategy instruction was expanded to include an explicitly self-regulatory focussed mnemonic (FAIL: From Attempts I Learn). Source analysis support (RAP: Read, Ask questions, Put into your own words) was positioned in close proximity to writing tasks. Drawing on the work of Fidalgo and colleagues (2015), group reading and writing was a consistent precursor to individual writing tasks. Similarly, informal verbal argument was a key element of classroom process, as this had been shown to stimulate topic specific thinking (Felton \& Herko, 2004). The graphing tool designed by Harris and 
colleagues (2008) was also amended in design and implementation (see Appendix 9). Each student's graph was managed (filled in) by the teacher. The graphs were then analysed by the students, for self-reflection and goal setting purposes. These graphs and verbal feedback during writing practice, on strategy use and goals, constituted the feedback from the teacher. The students first sighted the graphs after 4 pieces of writing were graphed; they could see the effects of the intervention against their pre-intervention efforts. This was done to take account of the work of Zumbrunn, Marrs and Mewborn (2015), identifying the complex emotional state adolescents bring to their learning, and the range of responses teacher feedback elicits in these learners. Finally, students could self-select writing templates, at intervention and at postintervention (see Appendix 8).

Argument writing was selected as the writing genre as it is of most benefit to the students as they progress through five years of Social Science education.

\section{Research Question}

The present study was guided by the following research question: Why is the SRSD method more effective for some students than for others, when applied to argument writing in a Tier 1 intervention?

\section{Quantitative Phase}

\section{Method}

Participants and Setting. Participants were between the ages of 12 and 14 years and belong to a learning group known as 923, a class of 27 female students. The class reflected the culturally and ethnically diverse nature of the school, and wider New Zealand society: 51\% identified as Pakeha/NZ European, 25\% identified as Māori, 14\% identified as Pasifika, 7\% identified as Asian, and 3\% identified as Middle Eastern. Five students who were absent for $10 \%$ or more of classes were excluded from the study. Thus, the final sample included 22 students.

Academically, the class was classified as mixed ability. Pretesting data, gathered on preentry to high school, indicated reading ability levels ranging between 3 Proficient and 6 Basic on the asTTle scale (see Appendix 4), with 4 Proficient being the expected level in Term 1 of Year 9 (tki.org.nz, 2016). Of the participants, 16 students sat above the expected level, with 6 of these students sitting well above the expected level. Five students sat well below the expected 4 
Proficient level. Two students had learning disabilities defined as challenging enough to qualify for teacher aide support. A teacher aide was assigned for one class in every 16 Social Studies classes. A further three students diagnosed with learning disabilities did not have allocated teacher aide support.

The study took place in a single gender (female) urban state secondary school in the lower part the north island of New Zealand. The intervention was implemented by the Social Studies teacher, who was also the primary researcher, working in a decile 8 state secondary school. Decile ranking is the measure of the school population which determines state funding per capita. Using National Census Data at 5 yearly intervals, based on enrolment data provided by schools, mesh blocks are generated. Within these, households are measured against 5 criteria; household income, occupation, household crowding, educational qualifications, and state provided income support. Whereas decile 1 schools are the $10 \%$ of schools with the highest proportion of students from low socio-economic communities, decile 10 schools are the $10 \%$ of schools with the lowest proportion of these students (MoE, 2016).

In the study population, one quarter of student homes meet the criteria for decile 1 schools, whereas a third meet the criteria for decile 10 status. Thus, the student sample was socio-economically and culturally diverse. The school operates a whole school restorative justice programme within its pastoral and academic programmes. Within the Social Studies classroom, Macfarlane's Educultural Wheel (Macfarlane, Glynn, Cavanagh, \& Bateman, 2007) is used to provide a culturally, academically and emotionally safe environment.

New Zealand teachers expected to develop a detailed local curriculum that is based on the New Zealand Curriculum (MoE, 2007) (NZC) framework. The entirety of the nationally mandated curriculum from years 1 -13 sits within a single, 49-page volume, under which teachers have the freedom to develop contexts that are valued by students. Within the target school, the Social Studies National Achievement Objectives (see Appendix 5) are implemented across a two-year junior secondary programme. While teachers have the freedom and the challenge of designing learning programmes that are relevant to the learning needs of all children, there are also explicit messages regarding pedagogical approaches: sufficient opportunities to learn; to create supportive learning environments; to encourage reflective thought and action; to help students to see the relevance of the learning, and make connections with prior learning and experience, and to facilitate shared learning. The NZC suggests that content learning will make way for skill learning given the time constraints on learning in the classroom environment (Hipkins, 2009, Ministry of Education, 2007, pp. 34-36). 
The Social Studies class was scheduled across a two-week timetable; Day 2: 8.40-10.20 am, Day 3: 1.20-2.10pm, Day 4: 11.30-1.05pm, and Day 10:1.20-3.30pm. The result of this scheduling is that students effectively attend Social Studies lessons four days in seven, and attend no Social Studies lessons for the remaining seven days in the fortnightly timetable cycle.

While the room allocated to the class changes once in the cycle (the Day 4 class operates in Room 24, rather than Room 23), the participants learn Social Science, English and Mathematics primarily in Room 23 - the assignment of learning to one Ako (reciprocal learning) space is deliberate and purposeful. Walls hold group developed work that is used as support for further individual and group tasks. Digital devices are mandatory learning tools through the school, although in the Social Studies class, students have the option of writing with devices, or using paper and pen.

Within the school, Social Studies as a discipline is departmentalised and the teachers of the department meet bi-monthly to align planning and assessment of learning. Simultaneously, a pilot cross-disciplinary learning approach, incorporating core subject teachers (Art, English, Mathematics, Science and Social Studies), entails weekly meetings that scope pastoral and pedagogical issues with the student group, as well as areas of collaborative learning across disciplines. This process aims to build a coherent curriculum that is student centred (MoE, 2007).

Social Studies is a compulsory subject in years 9 and 10. From Years 11 to 13, Social Studies comprises the optional and distinct disciplines of History, Geography, Classics, Economics, Sociology and Religious Studies. Course content at these levels is also at the discretion of the teacher, and is required to prepare students for the achievement standards of the National Certificates in Educational Achievement, under the New Zealand National Qualifications Framework. The junior Social Studies programme is the foundation for these senior subjects.

Design. A one-group pre-post design was used to compare writing performance, knowledge of argument writing, self-efficacy for writing, and writing self-regulation aptitude, before and after the intervention. In pre-intervention phase, students individually completed the writing knowledge questionnaire, writing self-efficacy scale, and self-regulation aptitude for writing scale. Also, students independently wrote three arguments related to different writing prompts. During the intervention phase, the classroom teacher provided SRSD writing instruction over a 22-week time frame. Students had three opportunities to write paragraphs, and one opportunity to write an argument essay using POW + TREE in this phase. The intervention 
included source analysis using RAP, and self-regulation using FAIL. In the post-intervention phase, students again completed the writing knowledge questionnaire, writing self-efficacy scale, and self-regulation aptitude for writing scale. They also wrote an argument essay in response to a writing prompt.

\section{Materials}

Instructional materials. Graphic designs of the four mnemonics: FAIL - From attempts I learn -; RAP - Read, ask questions, put in your own words -; POW - Pick an idea, Organise my notes, Write and say more -; TREE - Topic sentence, Reason, Evidence, Evaluative statement - were commissioned (see Appendix 1). These were displayed on classroom walls. Alongside these, a list of linking words was also displayed. These included firstly, secondly, thirdly, similarly, on the other hand, and conversely. Students constructed self-statement cards based on classroom discussions on how to maintain motivation in the face of challenges. These included phrases and questions such as "I'm on the right track" "Do I have evidence in my work?”, “Am I using my strategies? “.

Self-statement cards were generated by the students, drawing on class created material, and statements sourced from Pinterest. Graphs of writing progress were made on A4 sheets that contained grids to be filled, and indicators for linking words and counterarguments. (see Appendix 10). Graphs were used by the teacher to record student progress, and these were used by the students to set goals and gauge progress. Differentiated essay templates (see Appendix 8) were available to support student essay writing at intervention and post-intervention. During the intervention period, six of the NZC achievement objectives underpinned two learning programmes; 'What's the Real Cost?' a programme exploring the production of fashion clothing, and 'Why does Good Government Matter?', a programme comparing systems of government in New Zealand, a stable open society, with Syria, a state in civil war. Both the learning programmes and achievement objectives sit within the conceptual strands of the NZ Social Science Curriculum (see appendix 6). The selected conceptual strands (NZC,2007) are Identity, Culture and Organisation, and The Economic World. Drawn from Levels 3 and 4 of the Learning Objectives (NZC,2007), students learnt how 'groups make and implement rules and laws' and 'understand how producers and consumers meet their responsibilities and exercise their rights'. All content materials were drawn from the media, or were devised by teaching staff.

Originally configured as an iteration of Harris, Graham and Mason's POW plus TREE (2002) strategy, the intervention materials were adjusted and expanded as a response to both the assessment environment in New Zealand high schools, and a skill gap identified as still existing 
after a first term focus on research processes Thus RAP (Read, Ask questions, Put in your own words), a mnemonic to interpret source material, was added to POW, (Pick an idea, Organise your notes, Write and say more) plus TREE (Topic sentence, Reason, Evidence, Evaluative statement). Given that not all students were attempting the writing task within a formal assessment task, during the pre-intervention learning period, the mnemonic FAIL (From Attempts I Learn) was added to create an omnibus strategy approach (see Appendix 1). As a strategy directly addressing self-regulation, the mnemonic FAIL (From Attempts I Learn), complemented mnemonics already developed and well evidenced (Harris et.al.,2008). The mnemonic TREE was adjusted to Topic Sentence, Reason, Evidence, and Evaluative Statement, so that it reflected the expectations of paragraph structure within the New Zealand assessment environment.

Writing prompts. These were drawn from content material within the course. The students were asked to complete three pre-intervention prompts: (1) How would Horeta Te Taniwha have felt when the Endeavour arrived? or Do you think all cultures respond to each other like Horeta Te Taniwha and the Europeans? (2) What contribution has [your chosen cultural group] made to wider New Zealand Society? and (3) How useful is 'Long journey for sixpence' - an excerpt, in understanding the migrant experience in New Zealand? The intervention prompt was: Why is the film China Blue important? Finally, the post-intervention prompt was: Why is good government too important to leave to the politicians?

Self-efficacy for writing scale. This (SEWS; Zumbrunn et al., 2016) was used to assess students' beliefs about their writing ability. It consisted of 9 items that were rated on a 4-point Likert-type scale $(1=$ almost never to $4=$ almost always). Students were asked to circle the word that best reflected their thoughts. Example items include: "I can put my ideas into writing" and "I can write complete sentences." All items are provided in Appendix 7. Students completed the SEWS before $(\alpha=.76)$ and after $(\alpha=.68)$ the intervention.

Writing self-regulation aptitude scale. This (WSAS; Zumbrunn et al., 2016) was used to assess goal setting, planning, self-monitoring, attention control, emotion regulation, selfinstruction and help-seeking for writing. It consisted of 12 items that were rated on a 4-point Likert-type scale $(1=$ almost never to 4 = almost always). Example items include: "Before I write, I set goals for my writing" and "I think about how much time I have to write." All items 
are provided in Appendix 7. Students completed the WSAS before $(\alpha=.67)$ and after $(\alpha=.71)$ the intervention.

Measures. Writing knowledge and motivation data was coded using a procedure developed by Graham, Shirley and MacArthur (1993). Pre-intervention, intervention and postintervention work samples were gathered, and analysed using a coding procedure developed by Olinghouse, Graham and Gillespie, (2015). An argument essay contains an introduction, an ending, and several paragraphs, each comprising a clear statement, evidence, and explanation linking the two. A well-developed argument essay will contain linking words and counterarguments. Pre- and post-intervention samples were coded against 9 measures; Thesis Statement, Ending, Linking Words, Counter Argument, Word Count, Topic Sentence, Reason, Evidence, Evaluative Statement. Except for Word Count, these measures were coded as 0 - absent; 1 present, or 2 - present and developed (Olinghouse, Graham \& Gillespie, 2015). Multiple paragraphs were each individually coded, then averaged. Word count was measured using Microsoft Word.

Pre-intervention writing opportunities were, in the first instance, 30 minutes in-class using digital devices. In the second instance, an hour of class time was allowed, after three weeks' independent research and writing, using digital devices or pen and paper. This option was provided as a solution for students who were distracted by irrelevant digital material available through devices. In the third instance, 40 minutes in-class writing time, using pen and paper were allowed. No instruction on argument essay or paragraph writing was included in preintervention learning. Rather the focus was on accessing and interpreting information to answer a specific question - research skills.

Procedures. During the ten-week pre-intervention phase, students produced three written arguments, related to different written prompts. Thirty to forty minutes of class time was allocated to each of these. A week prior to the intervention phase, students completed the digital self-efficacy for writing scale, self-regulation aptitude for writing scale, and writing knowledge questionnaire. During the intervention phase, the Social Studies teacher supplemented content instruction with SRSD writing instruction, over twenty weeks. In the post-intervention phase students were allocated one hundred minutes to generate one piece of writing, in response to a written prompt. The digital self-efficacy for writing scale, self-regulation aptitude for writing scale, and writing knowledge questionnaire were again administered. After the first phase of quantitative data collection was completed, descriptive and inferential statistics were derived 
through a separate paired-samples t-test. This was used to compare pre-intervention and postintervention scores of the various outcome measures. Purposeful sampling was then applied to the quantitative data analysis; three pairs of students were selected against the criterion of the extent of written argument development, and an interview protocol was developed.

The fourth phase involved six individual interviews with students who showed low, moderate and high gains across the written argument variables. The interview transcriptions were then subject to coding and thematic analysis, within, and across cases. Finally, the quantitative and qualitative results were integrated and interpreted (see Appendix 13).

Intervention. The intervention began after final assessments from Term 1 learning had been returned. In this assessment, $75 \%$ of the class had opted not to attempt the paragraph writing aspect of the assessment. This was the 'well above the standard' element of the assessment. $33 \%$ of the class did not meet the criteria for achievement at the standard. The assessment task was set at Level 4 of the New Zealand Curriculum. The National Certificate in Educational Achievement assessments begin at Level 5 of the New Zealand Curriculum. The intervention began with the introduction of the FAIL mnemonic. This was supported at the outset by the viewing of a motivational video (https://www.youtube.com/watch?v=9kj-

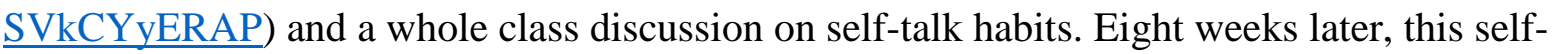
regulation support was revisited through the construction of self-statement cards, for students to have to hand when writing. All content learning materials were drawn from the media, or were devised by teaching staff to support learning objectives.

Working within the established culture in the room (Macfarlane et.al., 2007), the initial intervention step was a discussion about our emotional state interacting with our cognitive state during learning. FAIL was introduced as a tool to help us manage our emotional state, since anxiety can affect motivation for doing the 'hard thing'. The collective short-term goal was set as 'learning to write paragraphs so that an audience could clearly understand the message' - a process goal. The long-term goal was set as developing the skills and understanding to construct an argument essay - a process and product goal. The teacher was positioned as a learner in the process, with her own writing challenges to address.

RAP was then introduced as a tool for source analysis, and sources as essential for informing our point-of-view with explanation and evidence. An ongoing series of sources, both print and visual were provided for group analysis. RAP was modelled by the teacher, on the whiteboard, using an excerpt of text students would also use. Printed texts were divided into smaller sections for small group analysis, and RAPped. Each product was fed back to the whole 
class and collated as one class-constructed source. From this source, students would use POW and employ TREE to 'Write and say more'. Visual texts were RAPped using individual note making templates, that were then shared and compared in small groups. A collective agreement on points was reached through whole class discussion. Again, this was collated and displayed. Several sources were used across the intervention.

POW was modelled by the teacher, using class constructed source material. The 'Write and say more' aspect of POW was defined as the first step of paragraph construction, using TREE. Examples of paragraphs were evaluated against the TREE mnemonic, as a whole class, and in small groups. TREE was reconfigured to 'Topic Sentence, Reason, Evidence and Evaluative Statement', as the elements of a paragraph, as this is the established structure applied across classes for formal assessment tasks at National Certificate of Educational Achievement levels.

TREE was modelled by the teacher, on the white board, and practiced in small groups, for 20 - 30 minutes at three points across the intervention. Groups assessed their work against the TREE mnemonic, by identifying elements within the paragraphs, and marking these in the margins. The group work could then be drawn upon for individual efforts at paragraph construction. After practice at individual TREEs, templates were provided for argument essay construction. These templates were tri-levelled, each one constructed to meet the criterion for 'at the expected standard', 'above the expected standard' and 'well-above the expected standard' (see Appendix 8. Students self-selected a template.

Graphs of work were viewed and analysed for goal setting purposes at the outset of the intervention, and after each argument essay was completed. After the first essay was completed, and goals had been set from the graph, students constructed self-statement cards, which included graphics of FAIL, RAP, POW and TREE, as well as linking word prompts. These were then available on desks during writing sessions.

The mnemonics were drilled at the start of classes, and their purpose was iterated through lesson-opening quizzes. These quizzes also contained content questions, integrating the skill and content aspects of the course. Practice of RAP + POW or POW + TREE, collaboratively and individually, was embedded within the programme. Three extended writing sessions were available for essay construction. Homework was suggested, yet optional, and essay hand-in times were set three days after the writing session. Work was submitted for marking digitally.

Post-Intervention. Student constructed, teacher constructed, and media sources were available to the students, as were self-statement cards and mnemonics. Students selected an 
essay template during the planning phase, to write a response to "Why is good government too important to leave to the politicians?". A forty-minute planning session and one-hundred-minute writing session set aside to construct an argument essay. Submission of work was set three days after the writing session, so homework was an option. Immediately prior to these lessons, normal classes were suspended, and a whole day was spent working with, and listening to people who had been displaced by civil war.

\section{Treatment fidelity}

All lessons were recorded. Post-intervention, the recording of every third lesson was replayed for 20 minutes. SRSD instruction; modelling, discussion of mnemonic use, discussion of graphed progress, goal setting, or use of mnemonics in writing or research, group and independent, were found to be present across the sample.

\section{Interrater Reliability}

Content understanding grades, assessed against Key Understandings (see Figure 1), were moderated by a fellow subject teacher. Every fifth student's work was check marked by that teacher and agreement was found across all samples. Similarly, the rating of the argument essay variables was reviewed by an independent researcher. Every fourth post-intervention sample was checked, and all pre-intervention and intervention samples were also reviewed. Interrater reliability was $85 \%$.

\section{Social validity}

The intervention was developed and implemented by the classroom teacher, and was used to rework the usual approach to content learning and skill building. All writing samples were drawn from a programme that sits at the start of a five-year continuum of content learning and skill building. Both the teacher and students have a high level of satisfaction with the intervention. The intervention will be iterated across classes in future, indicating high social validity.

\section{Ethical clearance and informed consent}

Ethical approval was granted from Victoria University's ethics committee. Permission to conduct the research within the teacher's school was obtained from the principal. Parents and students were informed of the study and, given that the intervention formed normal classroom 
practice, both parental and student consent was taken as given, unless the forms declining participation were signed and returned. Students and parents received 3 updates on the learning intervention through the standard school digital reporting systems. Students were given the option to withdraw from the study at any time during the research, and were verbally reminded of this at three points during the intervention.

\section{Results and Discussion}

To provide a detailed account of possible changes in argument writing between preintervention and post-intervention, a separate paired-samples t-test was conducted on each component of argument writing.

With respect to writing performance, there was a statistically significant increase in the use of a thesis statement, $\mathrm{t}(21)=8.66, \mathrm{p}<.001$; use of an ending, $\mathrm{t}(21)=4.70, \mathrm{p}<.001$; use of linking words, $\mathrm{t}(21)=9.72, \mathrm{p}<.001$; and the use of counter-argument, $\mathrm{t}(21)=2.81, \mathrm{p}<.01$ (see Table 1). Further, there was a statistically significant increase in the use of topic sentences, $t(21)$ $=10.55, \mathrm{p}<.001 ;$ use of reasons, $\mathrm{t}(21)=7.57, \mathrm{p}<.001$; use of evidence, $\mathrm{t}(21)=6.18, \mathrm{p}<.001$; use of evaluative statements, $\mathrm{t}(21)=3.00, \mathrm{p}<.01$; and word count, $\mathrm{t}(21)=7.15, \mathrm{p}<.001$ (see Table 1). Thus, there was an increase in each of the nine measures of writing from preintervention to post-intervention.

The difference between scores on the self-efficacy for writing scale at pre-intervention $(\mathrm{M}=2.96, \mathrm{SD}=0.43)$ and post-intervention $(\mathrm{M}=2.28, \mathrm{SD}=0.38)$ were not significantly different, $\mathrm{t}(15)=1.19, \mathrm{p}=25$. Both pre-test and post-test scores were only provided by 16 students (11 students did not submit responses at both pre-test and post-test). Thus, despite improvements in writing performance, scores on the self-efficacy for writing scale did not change. Similarly, the difference between scores on the self-regulation aptitude for writing at pre-intervention $(\mathrm{M}=2.74, \mathrm{SD}=0.26)$ and post-intervention $(\mathrm{M}=2.84, \mathrm{SD}=0.37)$ were not significantly different, $t(15)=1.11, p=29$. Again, both pre-test and post-test scores were only provided by 16 students. Thus, despite improvements in writing performance, scores on the selfregulation aptitude for writing scale did not change.

Overall, these results indicate statistically significant gains across all measures of argument writing. However, despite the fact that all of these changes were statistically significant, only some of these changes were practically significant. These results will be discussed next, first the results that were both statistically and practically significant, followed by the results that were statistically significant but not practically significant. 
There were five findings that were both statistically and practically significant. First, word count showed large gains following the intervention. The use of POW and the injunction to "write and say more' had an impact, as their notes operated as an external memory, enabling them to write, while 'ticking off' their points. During the pre-intervention phase, no students made notes before writing; conversely, after the intervention, all of the students made notes before writing. Another possibly contributing factor was the TREE progress graph. Over the duration of the intervention, students indicated that they were motivated by the word count feature, and this may have encouraged them to extend their efforts.

Second, the impact of the TREE mnemonic from the intervention phase is apparent in the results. The use of the topic sentence was negligible at pre-intervention, but following the intervention, which included the modelling and identification of topic sentences, the use of topic sentences increased dramatically (see Table 1). Class and group construction of paragraphs enabled students to gain practice using topic sentences. Discussing the purpose of writing and topic of writing to an audience who needs to understand the issue may have contributed to the increase in the use of topic sentences.

Third, the use of reasons was the strongest feature of pre-intervention student writing. Nonetheless, there was a large increase in the use of reasons following the intervention (see Table 1). The students were comfortable from the outset about stating their positions and saying why they held these views. The provision of relevant sources and group analysis of these sources during the intervention phase, and the display of this work on the classroom walls, may have helped the students consider various reasons for peoples' views. As a result, students may have included more reasons in their writing. Further, this material could be included in their notes.

Fourth, evidence was emphasised in class discussions as the necessary feature of an argument. As with reason, this element of TREE was supported through the display of group and class work. Students were encouraged to see the choice of evidence as the justification for the argument. Observing paragraph writing and practice identifying evidence within paragraphs may have supported focus on the use of evidence in their writing. Further, in class discussions, students were asked to support their positions with evidence, or to seek the help of their peers to do so.

Lastly, the use of a thesis statement increased following the intervention. Before the intervention, none of the students included a thesis statement, whereas nearly all of them included one after the intervention. The essay template prompted students to use a thesis statement. This was also modelled on the board by the teacher. The students then independently wrote argument essays, without prior group practice. 
TABLE 1|

Mean and Standard Deviations for Measures of Writing Performance

\begin{tabular}{|l|c|c|c|}
\hline & Pre-Intervention & Post-intervention & \multirow{2}{*}{ Difference } \\
\cline { 2 - 3 } & $M(S D)$ & $M(S D)$ & +0.86 \\
\hline Thesis statement & $0.00(0.00)$ & $0.86(0.47)$ & +0.13 \\
\hline Ending & $0.00(0.00)$ & $0.13(0.59)$ & +0.82 \\
\hline Linking words & $0.00(0.00)$ & $0.82(0.40)$ & +0.27 \\
\hline Counter-argument & $0.00(0.00)$ & $0.27(0.46)$ & +2.69 \\
\hline Topic sentences & $0.40(0.37)$ & $3.09(1.23)$ & +2.83 \\
\hline Reasons & $1.03(0.24)$ & $3.86(1.89)$ & +2.30 \\
\hline Evidence & $0.74(0.30)$ & $3.04(1.76)$ & +0.15 \\
\hline Evaluative statements & $0.53(0.26)$ & $0.68(1.86)$ & +375.7 \\
\hline Word count & $74.4(28.6)$ & $450.1(257.9)$ & \\
\hline
\end{tabular}

There were four findings that were statistically significant, but not practically significant. First, the last element of the TREE paragraph, the evaluative statement, showed minimal gain after the intervention. This is a more challenging aspect of the writing structure. Most students focussed on replicating the first three elements of TREE (topic sentence, reasons, evidence) to produce multiple paragraphs. Some of the students made evaluative statements but this was not the norm. The use of evaluative statements is a sophisticated linking device, and only a limited number of students showed effective use of evaluative statements post-intervention. It may be that students needed additional practice in writing evaluative statements.

Second, few students wrote an ending. This was possibly by-product of the essay sequence; the ending was the last component of the writing task. And, it is possible that more time needed to be allocated to writing endings during instruction. Most students wrote an introduction as it is the opening of the essay. All students understood the task was to be completed in class time, but there was also the option of continuing for homework. Students who most enjoyed the task took this extension and wrote an ending. The majority of the students accepted the time constraints of the class and worked within these. As they had extensive notes prepared, they likely ran out of time, as they focussed their efforts on generously worded TREs.

Third, few students used linking words. Students were starting to use linking words, assisted by wall charts, personal prompts, and writing frames. However, these were not consistently used between all paragraphs. For instance, many students used only one linking word, despite writing three paragraphs. Possibly linking words were seen as peripheral to the construction of TREEs, and these were the primary focus of most students. Had time for revision been provided, perhaps this relatively sophisticated writing feature may have been developed more. 
Fourth, few students used counter-arguments. Most students were primarily focused on writing multiple TREEs in support of their point of view. The production of a counter-argument requires a shift in point of view that perhaps time, planning, and writing confidence did not allow. It is logical to focus on building the strongest argument first. Student selection from the three essay templates available suggests that this was the approach for the majority of the students. Of the three templates, only one contained a counterargument section. This was the longest and so most challenging structure. A minority of students selected that template as a guide, and a minority of those students developed a counter argument. Time constraints may again have played a role.

Overall, these results indicated that students' writing performance improved following the intervention, but that some skills developed to a greater extent than others. It is possible that additional time and practice could lead to practically significant improvements across all the measures.

\section{Qualitative Phase}

The quantitative phase indicated that while students showed an increase in argument writing performance, the extent to which their performance increased was not consistent across the sample. The follow-up qualitative phase enabled the investigation of student perception of the SRSD method on their writing knowledge development. Their self-efficacy for writing, and writing self-regulation could also be illuminated.

\section{Method}

Purposeful sampling. Criterion sampling involves selecting individuals who meet some predetermined criterion of importance (Johnson \& Christensen 2014). Criterion sampling was used to purposefully select three subgroups of students from the quantitative phase. The criterion was differences in argument writing performance. This was the criterion because the relative effectiveness of the SRSD intervention on argument writing performance was a key focus of the research. Student writing samples were scored on nine criteria; thesis statement, ending, linking words, counter argument, word count, topic sentence, reason, evidence, evaluative statement. To gain a range of perspectives, interviews were conducted with two students who showed high performance (i.e., they included all elements of an argument essay, and well-developed elements of TREE in their post-intervention sample), two who showed moderate performance (i.e., they included some elements of an argument essay, and produced some well-developed 
TREEs post intervention), and a final two who showed low performance (i.e., they are not yet using all elements of TREE, or well developed reasons or evidence, nor including argument essay elements ) across the nine measures.

Interview protocol. A semi-structured interview protocol was designed to prompt participants to describe their attitudes and beliefs about themselves as writers, and their argument writing knowledge. Further, they were asked to describe the social and learning support around them, in relation to writing (see Appendix 1). Within each guided interview, probe questions were included to follow-up students' initial responses.

Procedure. The individual interviews were conducted 7 weeks after the completion of quantitative phase. There was a 7-week gap between the quantitative phase and the interviews because the students were busy with other school-related activities, including a performance that was based on their Social Studies and English learning over the course of the year. The students were withdrawn from subject classes and interviewed by a graduate student with the Social Studies teacher present. The interviews took place during the mid-morning lesson in an available classroom within the school grounds. During the interviews, participants could view pre- and post-intervention writing samples, self-statement cards which included mnemonics, and graphs of their work to date. Interviews were audio recorded and lasted between 15-30 minutes each.

Data analysis and authenticity. The interview audio-recordings were transcribed verbatim by a research student, and coded independently by the research student and researching teacher. Interviews were analysed using thematic analysis (Braun \& Clarke, 2006), with the aim being to let the voices of the students be heard, rather than fitted to preconceived notions. As the first step in a five-step process, each coder read the transcripts several times independently. Interesting phrases were identified, as a holistic sense of the data also developed. No coding was applied to the data at this point. In the second step, interesting phrases that pertained to student perspective on the SRSD method as applied to argument writing and student sense of self were identified. For example, "I think learning how to shape it like using TREE and stuff like, that is, really helped cause I'm someone who likes to follow, like rule... like follow directions" indicates the perceived benefit of SRSD method, in relation to her preferred approach to tasks. Thirdly, initial codes were generated by segmenting and labelling extracted phrases. Some in vivo coding and some inductive coding was used to categorise relevant phrases. For the fourth step, categories were developed by aggregating similar codes together. For example, 'I feel 
doubt' and 'I feel stressed' were aggregated to 'Affective Issues' while 'these [mnemonics and self-statement cards] work', and 'I use these strategies now' were categorised as 'SelfSupporting' and 'Tool Use'. Consensus was reached on codes and categories through discussion. Theme identification was the fifth step. Categories were examined and compared to locate relevant relationships between and across categories. Four themes emerged: (1) seeing is believing; (2) time and purpose; (3) problems to overcome; and (4) my agentic self.

\section{Results and Discussion}

The data are described initially within each group, and then similarities and differences are described across the three groups (see Appendix 13).

\section{Within-group Analysis}

Low Performance Group. The first theme was seeing is believing; evidence of the individual's progress supported the acceptance that progress was being made. Both students in this group spoke with enthusiasm about their progress when they viewed their pre- and -post intervention writing samples. Comparing of samples and viewing of progress graphs led to statements pertaining to improved confidence and descriptions of how the work had improved. Both students used the TREE mnemonic to indicate how their writing had improved, following the intervention. For instance, when 1A was commenting on her pre-intervention writing sample, she remarked, “Honestly, I can't even tell what I'm writing about; there is no topic sentence." However, when commenting on her post-intervention writing sample, she could identify elements of TREE, stating "I have good reasons... and real, real strong, evidence."

Both students attributed the shift in their writing knowledge and self-efficacy to the use of the mnemonics RAP + POW +TREE. Student 1A stated that these helped "to organise my ideas and it all makes more sense". 1B identified a lack of structure in her pre-intervention sample, stating she has just "described the story", whereas she could identify that she "[had] done 4 TREEs" in her post-intervention writing sample. Both students were using the mnemonics to explain changes in their writing based on a comparison of their writing samples from before and after the intervention. These visual mnemonic prompts helped the students to recognize their writing progress.

The second theme was time and purpose: the perception of learning in relation to time, and reasons for improving writing. Student $1 \mathrm{~A}$ attributed her gain to her own effort, and the 
learning content, "I'm pretty good if I believe in it, like good government and Syria". 1A was prepared to work hard and use useful strategies when she believed in the significance of the learning. Whereas 1B found motivation for writing improvement in "thinking about the audience", rather than her belief in the significance of the learning. Each student identified another purpose for improving writing: 1A was determined not to get "bad marks" and 1B used self-talk to calm her "stress".

To this end 1B found TREE useful to "make it more clearer to read". Neither of these students discussed their writing development across time; they both spoke in the immediate term. Both identified writing performance improvement as a source of improved self-efficacy, and both expressed an interest in persevering in the face of transcription challenges.

With respect to theme 3, problems to be overcome (i.e., perceived difficulties with the writing process), there were similarities and differences within this group. 1B highlighted stress, panic, and the need to take time to look over her ideas; she referred to the mnemonic FAIL, to say, "In your head, you've got to try before you get it" when "you didn't do so well". She found all four mnemonics “pretty helpful, I don't think one's any more helpful than the others". Self-regulation was identified as a concern. Whereas $1 \mathrm{~A}$ did not mention stress or panic, but referred only to "stepping up her game" citing TREE as a useful tool to do so. Both students used the number of TREES as a positive measure of progress.

Both students explicitly identified transcription issues as a problem. Both would have liked more help with spelling and grammar and wanted to produce work that was "sophisticated". Like 1B, 1A identified "trouble like, maybe putting things in words and organising words and sentences". Both students described discussions with peers as either not occurring, or as about transcription issues, for example, "How do you spell this word?" Both students described discussions with family as "not really happening", though 1A was encouraged to read more by her mother, and 1B was advised to pay attention to grammar by her family.

While 1B found knowing whether her idea "is right or good enough" an issue, 1A had no difficulty with ideation, "I'll go with that idea because it is better". Both students recognised a good paragraph would contain a topic sentence, reasons and facts, and saw that these were more evident in their post-intervention writing.

Theme 4, my agentic self, refers to student perception of control of the learning process. Upon viewing the samples and progress graph, 1A expressed improved confidence and attributed her post-intervention shift - "I improved nine squares"- to her own effort and time: "I worked a lot, really hard on it, ... but this one, I did it really quickly, I didn't really think about it 
well, and I didn't put that much effort into it," in reference to her pre-intervention sample. She saw herself as agentic whereas Student 1B, while noting her improvement, and the usefulness of the mnemonics, attributed her performance to "having a good day," post intervention, and "having a bad day," pre-intervention. Both students stated that they did not read or write much outside of class, and "should" do more. 1A sought help in ordering her ideas from her mother, and noted that "talking privately" with the teacher helped her a lot. 1B liked to "check her work with the teacher", and received advice to work on grammar from her mother.

While $1 \mathrm{~A}$ was starting to use linking words, neither were able to fully recall the elements of an argument essay. Nor did their work contain counter-arguments, a thesis statement, or an ending. This indicated that while the strategies assisted the development of writing knowledge, and improved their self-efficacy and motivation, they were 'hitting a glass ceiling' due to a paucity of vocabulary and grammar knowledge.

Moderate Performance Group. The first theme was seeing is believing; evidence of the individual's progress supported the acceptance that progress was being made. For this group, the SRSD intervention appeared to improve their confidence in their writing performance; seeing the graphs and writing samples made 2A 'feel good', and 2B recognised she was in a 'good position'. 2A describes her pre-intervention sample as "all over the place, and the ideas are just kinda put there", whereas her post-intervention sample has ideas that "are sectioned off into paragraphs, and more organised. She rates her writing ability, out of ten, as having moved "to maybe a seven or an eight, just coz of how I've improved. At the start of the year I would definitely be so much lower like, I'd be a two or a three". She attributes these gains to "practice, RAP, POW and TREE, and support from people”.

2B describes her post-intervention sample as "a lot better than the first" and identifies RAP + POW + TREE as the processes that helped her "structure her writing better" in regard to her post-intervention sample. Although she describes herself as a person who "struggles to get her thoughts out" she also sees herself as more than "just above average". She described herself as shocked at seeing her pre-intervention sample, but felt "okay, seeing how I've improved over the year". Both students measured their improvement using the TREE mnemonic, which enabled them to locate paragraph features within their work.

The second theme was time and purpose: the perception of learning in relation to time, and reasons for improving writing. Both $2 \mathrm{~A}$ and $2 \mathrm{~B}$ ascribed a long-term purpose to their skill development. 2A said, "It's gonna be helpful in the future, especially for exams," and 2B said she "still needs to learn and expand, to improve and get higher up there", implicitly 
acknowledging she is on a learning trajectory. As to purpose, 2B stated she does not "really want to do the assessment", yet using the mnemonics "feels good because it helps me structure my writing”. 2A defined purpose as knowing "how to write, and write well, in a structured way". Both of these students saw writing as daunting, and recognised learning how to do it as useful across their subject areas.

Considering theme 3, problems to be overcome (i.e., perceived difficulties with the writing process), both students in this group identified self-regulation issues as problems to overcome. For instance, 2A stated, "I panic when I don't really have it", and she discussed the usefulness of FAIL, and the self-statement cards, in training herself to check that her planning was in order, and the elements of her paragraphs were present. 2B described herself as "not overly confident" and as someone who "find(s) it hard to come up with ideas".

2B described herself as using the mnemonics to "help me know what I'm doing", but still not being sure if her ideas are "wrong or right".

Theme 4, my agentic self, refers to student perception of control of the learning process. In this regard, $2 \mathrm{~A}$ recognised the generalisability of the strategies, describing writing as "not as easy as other subjects' and herself transferring the mnemonics to all her other classes, as it is 'following directions'. She enjoyed receiving positive feedback from those teachers in regard to her writing. She found writing 'easier now'. She was enthusiastic about the planning efficiencies the mnemonics enable, describing the structuring of her notes by TREEs.

2B also noted improved structure in her work, and yet she still struggled to believe in her own ideas. To address this doubt, she used POW to have her 'notes prepared so she can get started' on her essay writing. Interestingly $2 \mathrm{~A}$ recognised she could manage her affective state through strategy use, discussing FAIL and her self -statement card as tools that help her control her 'panic when she doesn't really have it', 'it' being an adequate sense of what is required, relative to what she is producing. Both students saw themselves as capable of making changes to their writing process and products, and were conscious of their affective states. 2A discussed the practical management of her anxiety more than $2 \mathrm{~B}$, who interpreted FAIL as 'you still have things to work on and improve', and she proved this to herself by observing her efforts. She addressed her ideation issues through extra preparation for writing.

They were respectful of the classroom environment and class relationships, and would persist when expected to in class. At post-intervention, time did not allow for the development of counter- argument in their work, and in discussion about the nature of argument essays, both students highlighted reasons and evidence to support points in paragraphs, rather than the larger essay structure. Both 2A and 2B were reserved in seeking help with writing from teachers or 
family members. Both students described their families as willing to offer advice and knowledgeable about writing because of their professions, and both had high academic expectations for themselves. They have made considerable progress in their approach to paragraph writing, and are constrained in their argument writing by doubt and panic.

High Performance Group. The first theme was seeing is believing; evidence of the individual's progress supported the acceptance that progress was being made. The SRSD writing intervention supported both students' confidence in their writing. Looking at her progress graph, 3A stated that "It shows I've got better so I have", 3B said "I feel much better now, and more self-confident in my writing" as a result of viewing her graph. She says she considered herself "about a 5 (out of ten) at the beginning of the year", even though she was "getting good grades and my teachers did say I was a good writer", whereas the explicit evidence in front of her, boosted her estimation to "maybe a 7 or an 8 ". Visual, measurable evidence is a powerful persuader. $3 \mathrm{~A}$ asserted that "this graph gave me confidence in that I have improved and made big improvements in one year".

The second theme was time and purpose: the perception of learning in relation to time, and reasons for improving writing. Interestingly, both students mentioned topic interest and class discussion as motivation for effort; 3A indicating increased enjoyment "if it's a really interesting subject" and 3B also discussed the culture of the class, "it was the whole class and I felt very involved and more interested in what was happening".

Considering time, 3A viewed her learning across decades, stating "there's always room for improvement, and when I look at my work from when I was five, things have definitely got better (laughs), and I think I can still get more better. And seeing how much I improved this year if I can do the same next year and then the next..." 3B discusses time as essential to the development of each piece of writing, and to avoid time pressure and the risk of work "not turning out well", will "wait a little, then talk to a few people, then I'll go back and I'll do it later". Both students saw the completion of the argument essay as the goal, and took time outside of class to achieve this. For example, 3B attributes her progress to "taking my own time out to try really hard and focus on my work"

Considering theme 3, problems to be overcome (i.e., perceived difficulties with the writing process), these students discussed only the practice and grasp of the mnemonics. During the intervention phase 3B needed to understand the specifics of the evidence component of TREE," Coz I would give evidence and I wasn't sure if it was reliable”. At post-intervention, she "simply just remembered FAIL", because "you don't need to be perfect". She describes her pre- 
intervention paragraphs as "just horrible, one big section, so no paragraph separation, and ramble". Post-intervention, she could "separate what I need to talk about and what I don't necessarily need". She used RAP and POW to develop detailed notes to work from. She also described liking "to think about what the opposing side would think about" and using this in argument essay writing.

3A needed time and practice to understand the mnemonics. She states that she "didn't really understand them, and just kind of ignored them", because she really preferred "story writing”, and did this for fun in her own time. However, she understood that a good writer will "do things that that you know will be good for it, even if you don't like to really", so she started "thinking about the audience" and used the mnemonics to help her "explain more clearly". To do this she addressed the problem of "getting stuck" and described her approach: "take a break", “don't give up when you get stuck" but "keep going 'cos 'from attempts you learn"”.

Theme 4, my agentic self, refers to student perception of control of the learning process, and these students used the strategies provided to their full extent. For example, 3A used the progress graph to set her own progress goals. Referring to the writing element 'transition words' and the measure 'not yet', she states “you can use that, and make your writing better next time. And you see in the next one I did use transition words, and it shows you what you can work on to make your next one better." She used the strategies to set achievable goals and worked to reach them. 3A also highlighted a key strength of the progress graph: "Not comparing yourself to others, but seeing your own improvement I think makes you more confident"

3B also positions herself fully in control of the learning process, stating "I don't want to put pressure on myself, I'll take a break, talk to a few people, go back to it later" when she is struggling, and choosing to put her own time into developing her writing skill.

$3 \mathrm{~A}$ and $3 \mathrm{~B}$ both enjoyed putting their thoughts and ideas on the page. They trusted the evidence in front of them, 'this graph shows I've got better so I have', and they found the mnemonics helpful, 'oh, I love these'. While they were clear that they had improved through strategy use, both 3A and 3B also knew that their practice and extra effort were reasons for their significant shift in argument writing. They could both describe elements of paragraphs and of argument essays. They both employed self-regulation strategies as a matter of course, 3A describing her approach thus, 'don't give up when you get stuck, do things you know will be good even if you don't like to really', and, when stuck, 'take a break, um, think about it for a while, then go back to writing, or ask someone, like I ask my mum'. Their sense of agency enabled them to 'just give it a go' and they willingly drew on the resources available to them. Both believed one needs to 'fail to succeed'. 
The high-performance group brought strong self-regulation to the learning from the outset, and a positive affect towards writing. From the intervention, they gained more discipline in their writing, and they were then more able to see the strength of their work. 3B stated 'I don't think I'm an incredible writer, but I'd say at the beginning of the year I was a 5 (out of a possible 10) because I was getting good grades and the teachers did say I was a good writer, but I feel much better and much more self-confident now in my writing'. For 3B seeing was believing (theme 1) when she could compare her work across the year, using the TREE graph, and her work samples. Interestingly, while the teachers were telling her she was doing well, she did not feel it was the case, until she saw the evidence. In her statement about her perception of herself as a writer, she also raised a cultural issue specific to New Zealand: the 'tall poppy syndrome'. There is a cultural tendency to understate one's success. 3A also discussed this issue, pointing out that 'if someone has a done a really good job and they feel quite proud of it they probably won't say 'oh, I've done a really amazing job of this, they feel bad about saying that?'

\section{Across Group Comparison}

Students' writing performance improved for all three groups following the SRSD intervention. Students discussed declarative, procedural and conditional knowledge of paragraph writing and strategy use. All students could state the elements of a paragraph, and the elements of the mnemonics. They also discussed how the mnemonics worked when they applied them to a writing task, and why they were effective in improving their writing. All groups could describe the elements of a paragraph and why these elements are useful, in terms of audience, for example 'evidence makes it stronger, so people will believe it'. While all groups could describe the mnemonics, in terms of function and effect, three students, 1B, $2 \mathrm{~B}$ and $2 \mathrm{~A}$, focused on how these managed their stress and panic. 1B and 2B described the mnemonics as helpful for planning and idea generation, whereas $1 \mathrm{~A}, 3 \mathrm{~A}$ and $3 \mathrm{~B}$ described them as enabling them to 'know' they are doing it. They were all in accord on the motivational effects of the SRSD method; their confidence had been enhanced by seeing their writing development graphed, and through comparing pre- and post-intervention samples.

Uniquely, the two students in the high-performance group both spoke positively of the culture in the room; 3B felt very involved and interested, and 3A pointed out that when topics were interesting, so were discussions, and consequently, writing could be enjoyable. Collaboration is important to them, while student to student comparison is not. In stating 'not 
comparing yourself to others, but seeing your own improvement I think, makes you more confident', 3A was speaking of common experience.

Post-intervention, only Group 3 could identify the elements of an argument essay, and only this group produced work which met the criteria for a developed argument essay. Group 2 members described self-regulation difficulties; lack of confidence in ability to write, or panic. Both students expressed a dislike of writing at the outset, and 2A spoke confidently of writing using strategies, enjoying that it is 'following directions', and she was applying the strategies in all her classes, and used self-talk to manage her anxiety. 2B, too, was applying the strategies to writing tasks while also contending with ideation issues.

While Group 3 was happy to persist with writing in their own time, Group 2 perhaps found calibration issues inhibited the choice of putting extra time and effort, outside of class, into the post-intervention essay. Like Group 1, they focussed on improving paragraph writing, rather than the challenge of the fully developed argument essay.

Both students in Group 1, on the other hand, put effort into their work outside of class, and this improved their paragraph writing. Group 1 produced work that contained elements of paragraphs, rather than an argument essay. These students both experienced transcription issues, and they wanted to use 'more sophisticated' language and sentence structure. The demands of writing, coupled with the challenge of limited vocabulary, likely precluded these students from yet grasping and demonstrating argument essay elements.

Student 1B, like student 2B, also experienced ideation and self-regulation issues. Problems to overcome, for Groups 1 and 2, are therefore more complex that those described by Group 3, whose only issues were to do with interpreting mnemonics.

Purpose was a key theme for Group 3. Practice for these students was worthwhile, as they were confident they could improve, and were prepared to risk the expenditure of extra effort. They explained their learning progress across a broad expanse of time, 'back when I was five', as did Group 2 students, who saw themselves as preparing for future academic success 'it's good for exams, apparently'. Group 1 students discussed their learning only in the present, and expressed motivation through 'not wanting to fail' (1A), and 'hoping to improve' (1B). Their sense of agency was markedly different to that of both other groups. Across the groups, purpose was critical to the students in that content influences their efforts. $1 \mathrm{~A}$ stated that 'believing in it' helped her write stronger work, and $3 \mathrm{~A}$ said when the topic is interesting she 'gets excited' about writing. 2A described writing on an uninteresting topic as, 'it's kind of just ugh, not fun', and 3B stated that when 'people aren't interested in it, they don't pay as much attention' and so they can't write much. Purposeful selection of learning context 
that is relevant to the students was appreciated. 1A commented that she knew her work 'was pretty good, it makes sense, and has a lot of evidence, 'cause I used evidence from Syria, it's big evidence because it's true', and she was drawing on personal experience.

Seeing is believing to all the students, and across the groups they knew they had made considerable progress in writing. 'I didn't even know what a paragraph was at the start of the year' (2A), and 'its [the mnemonics] helped me do better'(3B), are statements which sum up the experience of the sampled students. The degree to which the SRSD strategy has helped individual student's argument essay writing is dependent on the transcription, ideation and selfregulation issues that each student experiences.

\section{Integration of the Quantitative and Qualitative Results}

The quantitative data indicated that students' writing performance improved following the intervention, but that some skills developed more than others. The follow-up interviews provided information on students' perceptions of their writing development, and the social and cognitive support for the writing process. When the data sets were integrated, it was apparent that most students' declarative knowledge of paragraph writing had improved, but that only some of the students developed declarative knowledge of argument writing. No students discussed the purpose of all the writing performance measures, but all did describe elements of the TREE paragraph, and its effect on their approach to writing (see Table 2).

This may be a consequence of the intervention approach. This was broader than a focus on the structure of an argument essay. Students developed skills in research, and writing preparation, with a primary focus on writing TREE paragraphs. They also learnt to apply a selfregulation mnemonic, FAIL. Argument essays were positioned as an achievable outcome of the application of all the strategies and these were the emphasis of the intervention. The structure of argument essays was discussed and modelled by the teacher, and students were supported with argument essay templates. They then independently wrote argument essays.

It can be argued therefore, that students were independently writing TREE paragraphs, and were still working towards independent argument essay writing, at post-intervention. Some were still working towards strong TREE paragraphs: the quantitative data shows that the evaluative statement, the final E, was not yet practically significant across the group. In interviews, students discussed FAIL + RAP + POW + TREE and the combined effect of these, and their progress graphs, on their writing. The evidence suggests all groups have improved their procedural knowledge of paragraph writing using mnemonics, and their efforts produced more 
coherent text which makes it easy for an audience to understand their point of view. The four mnemonics have also supported improved conditional knowledge of writing, research and selfregulation. Students will use FAIL when they feel anxious, for example. They use RAP and POW to gather sufficient material to develop into TREEs. They use TREE to assess the completeness of their work. Seeing TREEs in their work motivates them continue to create them.

All groups made significant gains in the amount of text generated after the intervention. They are more willing and more able to respond to prompts and generate structured writing because of the SRSD method applied to writing and embedded within a learning programme. While some are generating enough TREEs for a 'forest', and others just enough for a 'copse', all have made progress because of the intervention.

While all students wrote reasons for their point of view pre-intervention, these were stronger and more consistent post-intervention. Evidence is a significant variable in this study, as it is a key measure of argument strength; it was challenging for the students to grasp. Perhaps consequently, the data reveals it to be the variable with the most diverse shift, with no shift for the low and medium groups, and strong shift for the high group. Students in the high group state that "I struggled with evidence", until they understood what "good evidence was". The medium group were using evidence, yet not developing it as much. Their perseverance was affected by their affective state; "I'm not as good at writing as other subjects...I panic", "I'm not sure if I am right".

The low gain group make small gains in use of evidence, and decline in evaluative statements. They describe evidence as making a paragraph strong. These students discuss transcription issues as their biggest concern about the writing process. Moderate gain group interviews suggest that argument essay development was hampered by self-doubt, and the use of the mnemonics as strategies positively assisted the students to manage their anxieties. This group makes some use of thesis statement, linking words and endings, pointing to a nascent grasp of argument essay structure. The strategies are described in transferrable terms, "it is a pattern to be followed" and can be applied "in any subject". The high group, competent and confident writers, also know this, and demonstrate the strongest gains across all measures of argument essay writing. They possess strong self-regulation skills and can position learning as a process that they can control: "when I'm stuck, I take a break...I talk to people", and one has "fail to succeed". These attributes enabled them the cognitive space and motivation to succeed in the development of argument essay writing. This group singularly incorporated counter argument into their writing, and mentioned that verbal debate assisted them to do so. Anticipating the opposition's point of view "made their argument stronger". 
The data integration indicates that students improved their understanding and execution of paragraph writing, and self-regulation strategies for writing. Progress has been made towards argument essay writing through the SRSD intervention. 


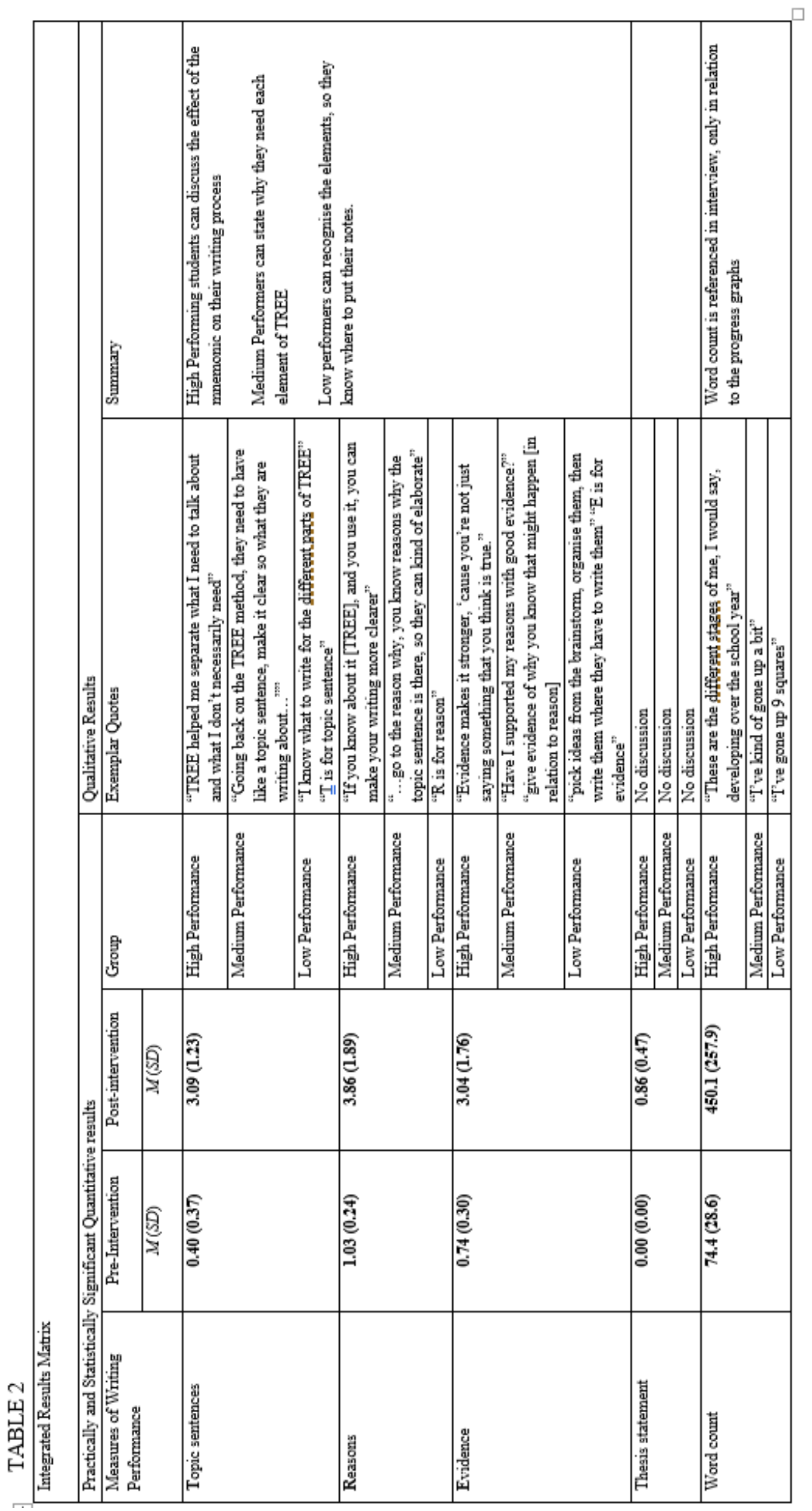




\section{Limitations}

While the SRSD intervention had a positive effect on student writing and performance, and possible reasons for limited gains are explored, there are some limitations and challenges within the study. This one-group pre-post design lacks a control group. Without comparison with another class learning the same content without the SRSD intervention, it is not possible to provide causal evidence for the relative effectiveness of SRSD intervention.

The expected triangulation between questionnaire data, writing product data, and selectively sampled interview data was not possible due to flawed implementation procedures with the questionnaires. There was also a lack of alignment between the writing knowledge scales and the intervention instruction. For example, the scales considered spelling and punctuation, and these were not included in the intervention. These instruments were to assess reliability, but under or overconfidence in participants' skill estimation at pre-and /or postintervention may have rendered the data invalid.

The integration of qualitative data with quantitative data was also problematic. The interviewees opted to discuss SRSD strategies that contributed to writing performance; FAIL + RAP + POW + TREE, and this did not enable an in-depth analysis of the student perception of the 9 argument writing measures.

The nature of the learning programme the SRSD intervention sat within was different between pre- and post- intervention. It is possible the inclusion of first-hand accounts of civil war influenced affective dispositions among the study sample, and this influenced motivation for writing. The students felt the learning more keenly, and this may have been reflected their efforts.

Both digital and pen to paper options were available to the students, as means for writing product generation. This option, designed to generate a sense of ease with the process, may have affected results, as digital text generation can be faster than hand writing.

The timetabling of the class, combined with other activities in the school may have affected text production; the writing samples were not generated at a consistent time of day. While allowing the option of extra time to finesse work is good pedagogical practice, the variable time constraints affect the data comparison.

\section{Future Research Directions}

Future research could usefully continue to measure the effectiveness of Tier 1 SRSD on adolescent social science writing. This study ran for two terms within a Year Nine Social Studies 
programme. Extending an SRSD intervention, in writing, across a longer time frame may produce data on 'closing the gap' between the low gain and high gain students. Research into transcription support programmes, digital or hard copy, run in conjunction with SRSD writing intervention, may point the way for practitioners seeking to address the range of needs within any given classroom.

From a practitioner point of view, it would also be interesting to apply SRSD methods to a full teaching programme, to test its effect on teacher work load, in conjunction with student skill gain. Methods which enable all students to progress within a Tier 1 environment are necessary to address education equity issues. A study that examines the culture in the room, 'the pulse of the place' (Macfarlane et.al., 2007), and SRSD methods in teaching writing may further contribute to managing diverse learning needs in the classroom. Te Ao Maori approaches to learning and SRSD method seem a synchronous fit. Consideration of physical environment and social factors and SRSD is another area for further research. Within this, the positioning of the teacher / student relationship and SRSD interventions may also be a fruitful area of inquiry.

The development of scales to measure genre features, for example evidence and reason in argument essay argument writing, would also support further research on argument essay writing.

Finally, studies of teacher approaches to writing practice within secondary subject disciplines, and within teacher training programmes, would be informative. Given that writing is the primary means of assessing academic progress, the paucity of teacher training in writing instruction appears to be a structural gap across which teachers and students currently stumble.

\section{References}

Applebee, A. N., \& Langer, J. A. (2011). " EJ" Extra: A Snapshot of Writing Instruction in Middle Schools and High Schools. The English Journal, 100(6), 14-27.

Bandura, A. (1986). The explanatory and predictive scope of self-efficacy theory. Journal of social and clinical psychology, 4(3), 359-373.

Bandura, A. (1997). Self-efficacy: The exercise of control. New York: Macmillan.

Bereiter, C., Burtis, P. J., \& Scardamalia, M. (1988). Cognitive operations in constructing main points in written composition. Journal of memory and language, 27(3), 261-278.

Bishop, R., \& Berryman, M. (2006). Culture speaks: Cultural relationships and classroom learning. Wellington, New Zealand: Huia Publishers.

Bishop, R., Berryman, M., Cavanagh, T., \& Teddy, L. (2009). Te kotahitanga: Addressing 
educational disparities facing Māori students in New Zealand. Teaching and Teacher Education, 25(5), 734-742.

Bruning, R., Dempsey, M., Kauffman, D. F., McKim, C., \& Zumbrunn, S. (2013). Examining dimensions of self-efficacy for writing. Journal of Educational Psychology, 105(1), 25.

Bruning, R. H., \& Kauffman, D. F. (2015). Self-efficacy beliefs and motivation in writing development. In C. A. MacArthur, S. Graham, \& J. Fitzgerald (Eds.), Handbook of writing research. (2nd Ed., pp 160-173) New York: Guilford Press.

Graham, S., Capizzi, A., Harris, K. R., Hebert, M., \& Morphy, P. (2014). Teaching writing to middle school students: A national survey. Reading and Writing, 27(6), 1015-1042.

Creswell, J. W., Klassen, A. C., Plano Clark, V. L., \& Smith, K. C. (2011). Best practices for mixed methods research in the health sciences. Bethesda (Maryland): National Institutes of Health, 2094-2103.

De La Paz, S., \& Graham, S. (2002). Explicitly teaching strategies, skills, and knowledge: Writing instruction in middle school classrooms. Journal of Educational Psychology, 94(4), 687.

De La Paz, S. (2005). Effects of Historical Reasoning Instruction and Writing Strategy Mastery in Culturally and Academically Diverse Middle School Classrooms. Journal of Educational Psychology, 97(2), 139.

De La Paz, S., \& Felton, M. K. (2010). Reading and writing from multiple source documents in history: Effects of strategy instruction with low to average high school writers. Contemporary Educational Psychology, 35(3), 174-192.

De La Paz, S., Felton, M., Monte-Sano, C., Croninger, R., Jackson, C., Deogracias, J. S., \& Hoffman, B. P. (2014). Developing historical reading and writing with adolescent readers: Effects on student learning. Theory \& Research in Social Education, 42(2), 228274.

Felton, M. K., \& Herko, S. (2004). From dialogue to two-sided argument: Scaffolding adolescents' persuasive writing. Journal of Adolescent \& Adult Literacy, 47(8), 672-683.

Fidalgo, R., Torrance, M., Rijlaarsdam, G., van den Bergh, H., \& Álvarez, M. L. (2015). Strategy-focused writing instruction: Just observing and reflecting on a model benefits 6th grade students. Contemporary Educational Psychology, 41, 37-50.

Graham, S., Schwartz, S. S., \& MacArthur, C. A. (1993). Knowledge of writing and the composing process, attitude toward writing, and self-efficacy for students with and without learning disabilities. Journal of Learning Disabilities, 26(4), 237-249.

Graham, S., Harris, K. R., \& Mason, L. (2005). Improving the writing performance, 
knowledge, and self-efficacy of struggling young writers: The effects of self-regulated strategy development. Contemporary Educational Psychology, 30(2), 207-241.

Graham, S., \& Perin, D. (2007). A meta-analysis of writing instruction for adolescent students. Journal of Educational Psychology, 99(3), 445-476.

Harris, K. R., Graham, S., Mason, L. H., \& Saddler, B. (2002). Developing self-regulated writers. Theory into practice, 41(2), 110-115.

Harris, K. R., Graham, S., Brindle, M., \& Sandmel, K. (2009). Metacognition and children's writing. In D Hacker, J Dunlowsky \& A Graesser (Eds.), Handbook of Metacognition in Education, (2nd Ed., pp 131-153), .New York: Routledge

Harris, K. R., Graham, S., Mason, L. H., \& Friedlander, B. (2008). Powerful writing strategies for all students. Baltimore, Maryland: Paul H Brookes Publishing Co.

Hawthorne, S. (2008). Students' beliefs about barriers to engagement with writing in secondary school English: A focus group study. The Australian Journal of Language and Literacy, 31(1), 30.

Hipkins, R. (2009). Reshaping the secondary school curriculum: Building the plane while flying it. Findings from the NZCER National Survey of Secondary Schools. Wellington. New Zealand: NZCER

Johnson, B., \& Christensen, L. (2014). Educational research: Quantitative, qualitative, and mixed approaches. London, UK: Sage.

Limpo, T., \& Alves, R. A. (2013). Modelling writing development: Contribution of transcription and self-regulation to Portuguese students' text generation quality. Journal of Educational Psychology, 105(2), 401.

Limpo, T., \& Alves, R. A. (2013). Teaching planning or sentence-combining strategies: Effective SRSD interventions at different levels of written composition. Contemporary Educational Psychology, 38(4), 328-341.

McKeown, D., Brindle, M., Harris, K. R., Graham, S., Collins, A. A., \& Brown, M. (2016). Illuminating growth and struggles using mixed methods: Practice-based professional development and coaching for differentiating SRSD instruction in writing. Reading and Writing, 29(6), 1105-1140.

Macfarlane, A., Glynn, T., Cavanagh, T., \& Bateman, S. (2007). Creating culturally-safe schools for Māori students. The Australian Journal of Indigenous Education, 36, 6576.

Ministry of Education (2007) New Zealand Curriculum Retrieved from http://nzcurriculum.tki.org.nz/ August 212016 
Olinghouse, N. G., Graham, S., \& Gillespie, A. (2015). The relationship of discourse and topic knowledge to fifth graders' writing performance. Journal of Educational Psychology, 107(2), 391.

Pajares, F. (1996). Self-efficacy beliefs in academic settings. Review of educational research, 66(4), 543-578.

Pajares, F., Johnson, M. J., \& Usher, E. L. (2007). Sources of writing self-efficacy beliefs of elementary, middle, and high school students. Research in the Teaching of English, 104-120.

Pajares, F. (2003). Self-efficacy beliefs, motivation, and achievement in writing: A review of the literature. Reading \&Writing Quarterly, 19(2), 139-158.

Ray, A. B., Graham, S., Houston, J. D., \& Harris, K. R. (2016). Teachers use of writing to support students' learning in middle school: A national survey in the United States. Reading and Writing, 29(5), 1039-1068.

Santangelo, T., Harris, K. \& Graham, S. (2016). Self-Regulation and Writing: Meta-Analysis of the Self-Regulation Processes in Zimmerman's and Risemberg's Model. In C. A MacArthur, S. Graham, \& J. Fitzgerald (Eds.), Handbook of Writing Research $\left(^{\text {nd }}\right.$ Ed., pp 174-193), New York: Guilford Press.

Schunk, D. H., \& Pajares, F. (2009). Self-efficacy theory. In K Wentzel \& A Wigfield (Eds.) , Handbook of Motivation at School (pp. 35-53) New York: Routledge.

Schunk, D. H., \& Zimmerman, B. J. (1994). Self-regulation of learning and performance: Issues and educational applications. (p.56) London, UK: Lawrence Erlbaum Associates, Inc.

Schunk, D. H., \& Zimmerman, B. J. (1997). Social origins of self-regulatory competence. Educational psychologist, 32(4), 195-208.

Usher, E. L., \& Pajares, F. (2008). Sources of self-efficacy in school: Critical review of the literature and future directions. Review of educational research, 78(4), 751-796.

Washburn, E., Sielaff, C., \& Golden, K. (2016). The Use of a Cognitive Strategy to Support Argument-Based Writing in a Ninth-Grade Social Studies Classroom. Literacy Research and Instruction, 55(4), 353-374.

Wilcox, K. C. (2014). An Urban Secondary School Case Study of Disciplinary Writing in Tracked Classrooms. Education and Urban Society, 47(2), 242-268.

Wilcox, K. C., \& Jeffery, J. V. (2015). Adolescent English language learners' stances toward disciplinary writing. English for Specific Purposes, 38, 44-56.

Wong, B. Y., Hoskyn, M., Jai, D., Ellis, P., \& Watson, K. (2008). The comparative efficacy 
of two approaches to teaching sixth graders opinion essay writing. Contemporary Educational Psychology, 33(4), 757-784.

Zigmond, N. (2006). Reading and writing in co-taught secondary school social studies classrooms: A reality check. Reading \& Writing Quarterly, 22(3), 249-268.

Zimmerman, B. J., \& Risemberg, R. (1997). Caveats and recommendations about selfregulation of writing: A social cognitive rejoinder. Contemporary Educational Psychology 22 (1), $115-122$.

Zimmerman, B. J., \& Kitsantas, A. (1999). Acquiring writing revision skill: Shifting from process to outcome self-regulatory goals. Journal of Educational Psychology, 91(2), 241.

Zimmerman, B. J., \& Schunk, D. H. (2001). Reflections on Theories of Self-regulated learning and academic achievement. In B.J Zimmerman \& D.H Schunk (Eds.), Selfregulated learning and academic achievement: Theoretical perspectives. $\left(2^{\text {nd }} E d ., p\right.$ 275), New York: Routledge.

Zimmerman, B. J. (2002). Becoming a self-regulated learner: An overview. Theory into practice, $41(2), 64-70$.

Zito, J. R., Adkins, M., Gavins, M., Harris, K. R., \& Graham, S. (2007). Self-regulated strategy development: Relationship to the social-cognitive perspective and the development of self-regulation. Reading \& Writing Quarterly, 23(1), 77-95.

Zumbrunn, S., Marrs, S., \& Mewborn, C. (2016). Toward a better understanding of student perceptions of writing feedback: a mixed methods study. Reading and Writing, 29(2), 349-370. 
Appendices

Appendix 1 

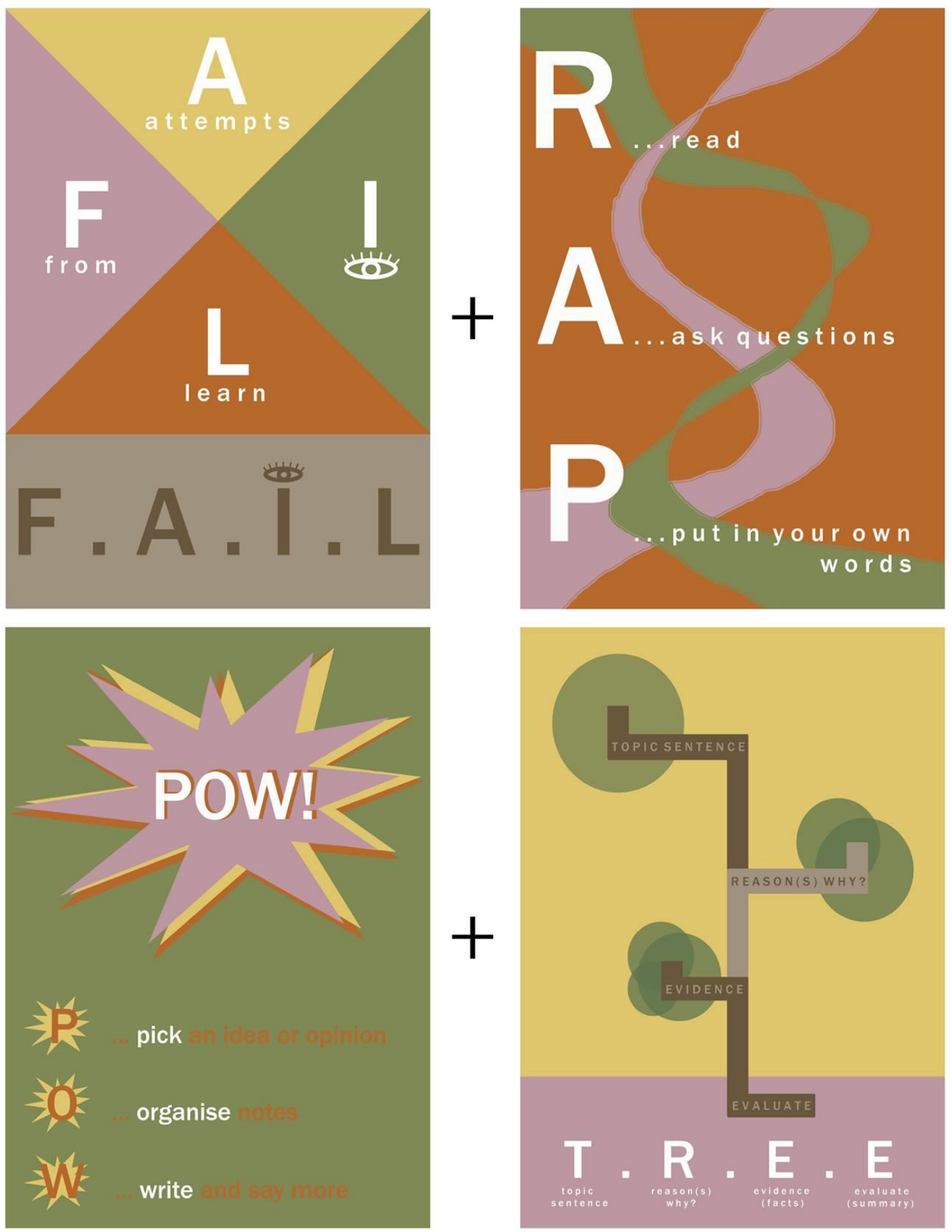


\section{Appendix 2}

\section{The Educultural Wheel}

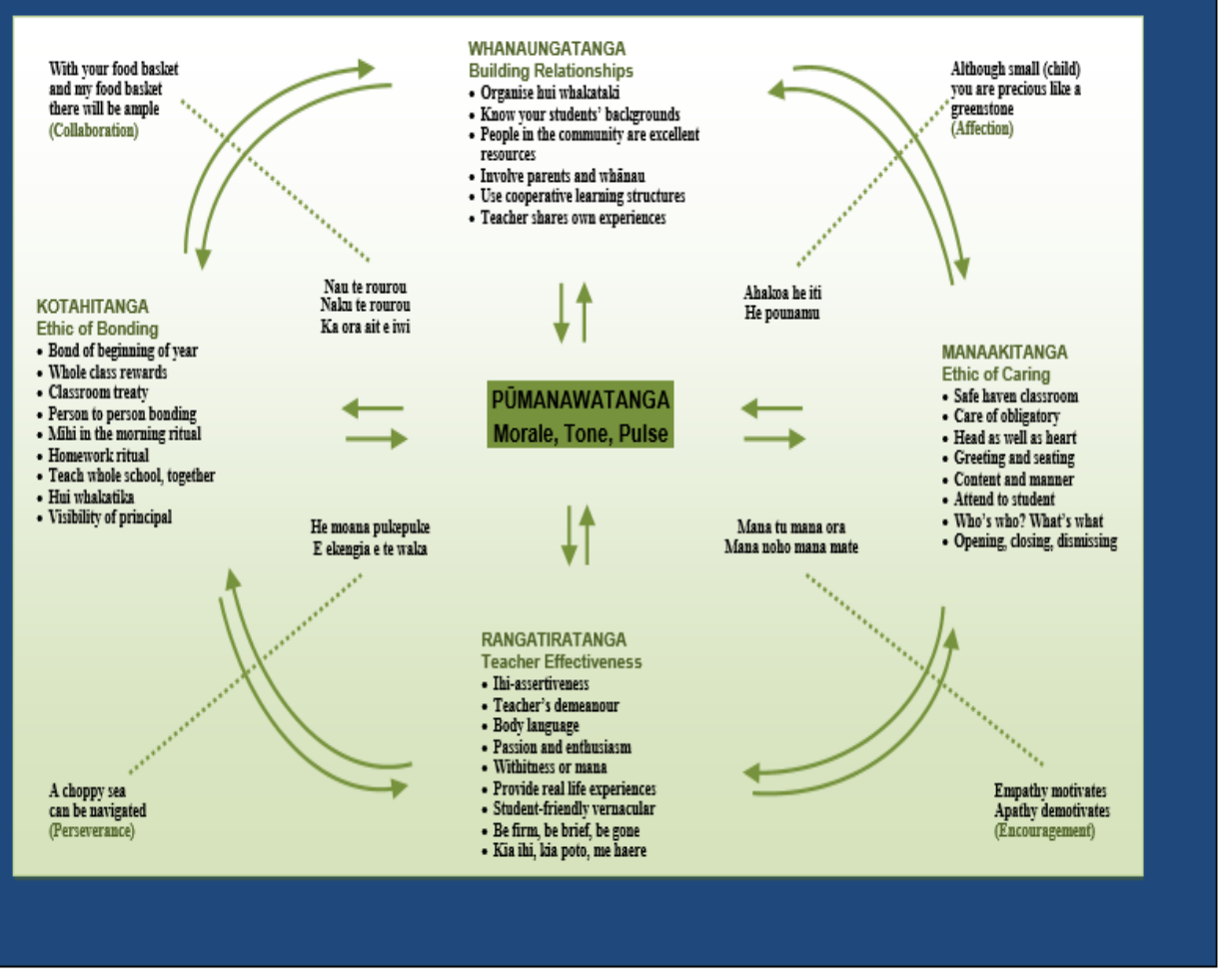

Macfarlane, A. (2004) Kia hiwa rā! Listen to Culture: Māori students' plea to educators. Wellington: NZCER. 


\section{Appendix 3}

\section{EXPLANATORY SEQUENTIAL DESIGN}

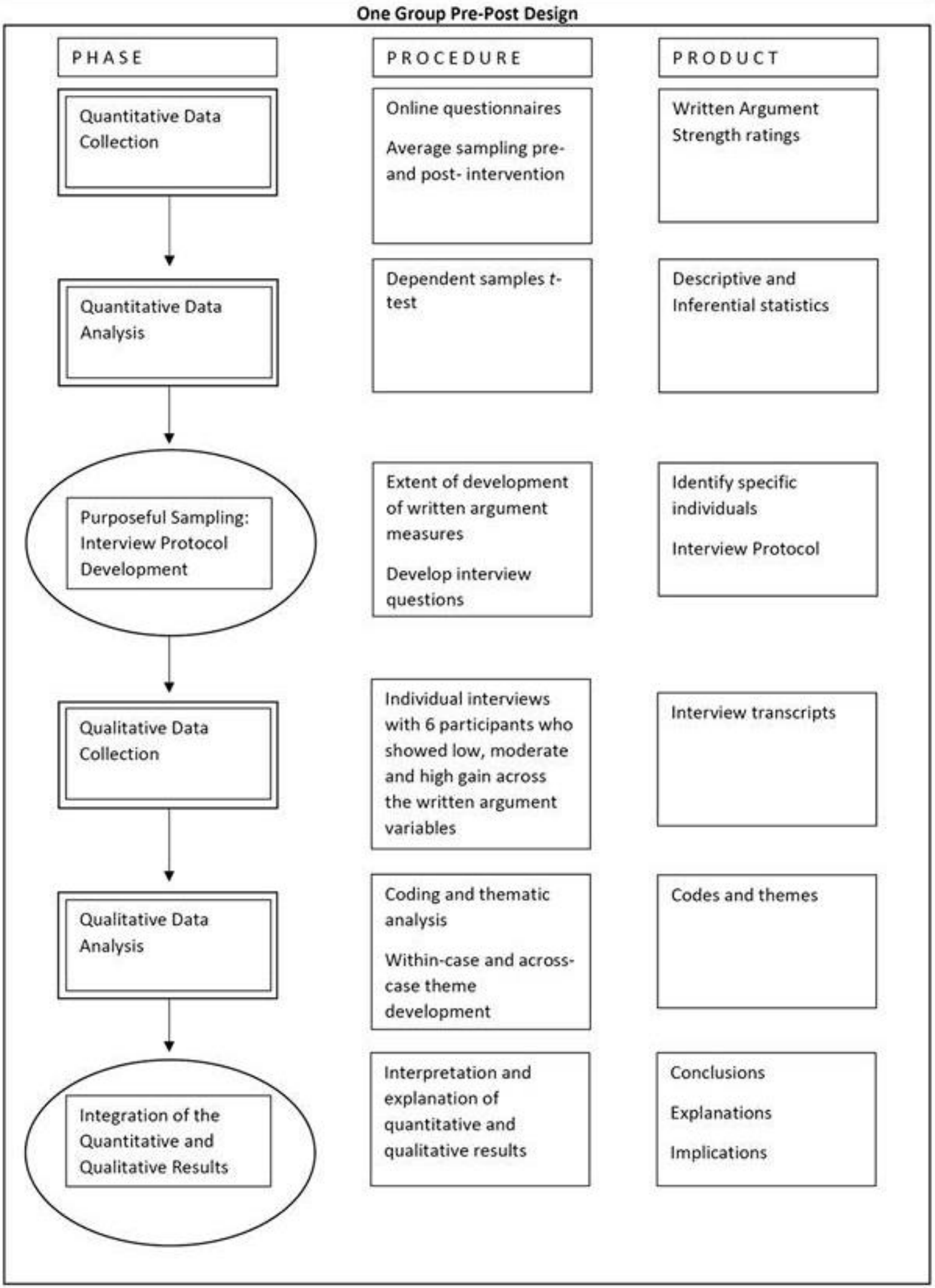




\title{
Appendix 4
}

\author{
e-asTTle Norms
}

The tables below show the e-asTTle norms and curriculum expected for each subject by year level and time of the year.

The e-asTTle norms differ from the curriculum expectation. The curriculum expected indicates how an average student in each year level should be progressing, according to the New Zealand curriculum documents. The norms, however, indicate how the average student in New Zealand is progressing in the subject. The norms reflect the data collected in the asTTle CD-ROM and e-asTTle pilots.

The norms are calculated from the aggregated results of over 150,000 students in each of reading and mathematics. When e-asTTle scores are generated, they take into account the level of the questions asked. There are many possible different permutations of e-asTTle items, creating tests that vary widely in content, spread and difficulty. It should be noted that the norms are not specific to tests of a specific curriculum level or type. They are instead based on the combined data from all types of e-asTTle tests within an appropriate curriculum range.

Only tests that are considered within an appropriate curriculum range for each year level are included in the norming process. For example, while it is possible to adminster a Year $\theta$ student any level of test, only tests between $3 \mathrm{~A}$ and $5 \mathrm{~A}$ are included in the norming process. This avoids skewing the data from tests where the minimum or maximum possible scores are very low or very high.

The average values are calculated using rolling means across the quarters, ensuring that the e-asTTle norms will always increase across the year. It should be noted that scores need to be at least 22 points apart before we can assume a non-chance difference. Thus, for example, while the 'Number Knowledge' average is 1530 in Year 8, Quarter 2 and the corresponding 'Probability' score is 1516, we cannot necessarily conclude the Year 8 students are performing better in Number Knowledge than in Statistics.

There are some year levels in e-asTTle where there have been insufficient numbers of appropriate tests to generate justifiable norms. This is particularly evident at Years 10-12. At these year levels, there is a potential selection bias, where the data is representative of particular ability range of students. To mitigate the effects of non-representative sampling. norms have been adjusted to reflect appropriate score values. These norms will be updated in future years as e-asTTle is used further by students at the upper year levels. 
e-psTTle Norms and Curriculum Expectation by Quarter: Reading

\begin{tabular}{|c|c|c|c|c|}
\hline Duniter & For & $\begin{array}{l}\text { Ment } \\
\text { Bure }\end{array}$ & $\begin{array}{c}\text { Whin LuT oulum } \\
\text { Lewe }\end{array}$ & 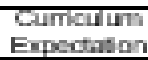 \\
\hline 1 & 4 & $\tan 1$ & 5 & 괌 \\
\hline \pm & 4 & 1 1]Et & 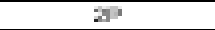 & III \\
\hline 3 & 4 & itำ & 5 & IF \\
\hline 4 & 4 & 14as & \pm & Iit \\
\hline 1 & 5 & 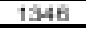 & 5 & 교 \\
\hline 2 & $\mathrm{~s}$ & 119en & 24 & IA \\
\hline 3 & s & 1372 & 24 & IA \\
\hline 4 & 5 & 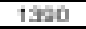 & 5 & 3 표 \\
\hline 1 & 들 & 148 & syly & 3日 \\
\hline 른 & E & 14i4tit & 하 & 3i \\
\hline 3 & 흐 & $14 \mathrm{an}$ & 해낸. & 표 \\
\hline 4 & E & 14at & 54 & בip \\
\hline 1 & $T$ & 1430 & sis & בק \\
\hline 2 & $F$ & 1434 & sin & $3 A$ \\
\hline 3 & $F$ & 1447 & $4 B$ & $3 A$ \\
\hline 4 & $F$ & 144 넬 & AB & 48 \\
\hline 1 & E & $1+42$ & $4 B$ & 48 \\
\hline 2 & B & $14 f^{2}$ & 4 & 41 \\
\hline 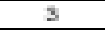 & E & 1404 & 4 & 41 \\
\hline 4 & $E$ & $14=$ & 49 & 4 \\
\hline 1 & $D$ & 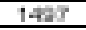 & 4 & 41 \\
\hline 2 & $D$ & 17abe & 난 & $4 \overline{4}$ \\
\hline 3 & $D$ & 1 15aT & 4 & -44 \\
\hline 4 & $D$ & 15ide & 4 & EH \\
\hline 1 & DE & $15 \mathrm{set}$ & 4 & 표 \\
\hline 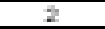 & Da & $15 \mathrm{gln}$ & 4 & ST \\
\hline 3 & "a & 1345 & 4 & El \\
\hline 4 & -0 & 1 1락 & 5 & EA \\
\hline 1 & $\pi 1$ & 1품ㅁㅁ & 나강 & EA \\
\hline 2 & \pm 1 & $1 \mathrm{A12}$ & 툐 & ES \\
\hline 3 & $\pi 1$ & 1 16.2. & SI & ets \\
\hline 4 & 11 & 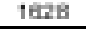 & 5 & हो \\
\hline 1 & 4 & 1034 & 5 & tep \\
\hline 2 & 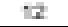 & 10445 & $\mathrm{~EB}$ & 醉 \\
\hline 3 & 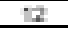 & 10Es & $t 5$ & is \\
\hline 4 & 12 & $1 \mathrm{its} T$ & $t=$ & EA \\
\hline
\end{tabular}

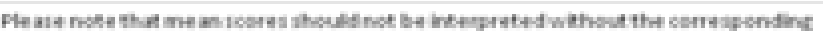
ceriloulumberk

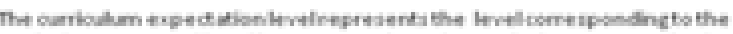

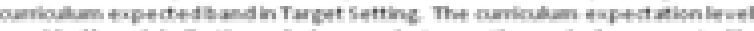

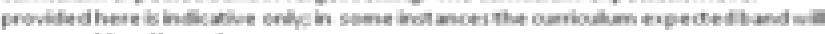

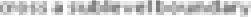




\section{Appendix 5}

\section{New Zealand Curriculum Objectives - Social Studies}

Students will gain knowledge, skills, and experience to:

Social studies at Level 3

Understand how groups make and implement rules and laws.

Understand how cultural practices vary but reflect similar purposes.

Understand how people view and use places differently.

Understand how people make decisions about access to and use of resources.

Understand how people remember and record the past in different ways.

Understand how early Polynesian and British migrations to New Zealand have continuing significance for taogata whenua and communities.

Understand how the movement of people affects cultural diversity and interaction in New Zealandm

Students will gain knowledge, skills, and experience to

Social studies at Level 4

Understand how the ways in which leadership of groups is acquired and exercised have consequences for communities and societies.

Understand how people pass on and sustain culture and heritage for different reasons and that this has consequences for people.

Understand how exploration and innovation create opportunities and challenges for people, places, and environments.

Understand that events have causes and effects.

Understand how producers and consumers exercise their rights and meet their responsibilities.

Understand how formal and informal groups make decisions that impact on communities.

Understand how people participate individually and collectively in response to community challenges

Sourcedfrom the New Zeaiand Curiculan, (MoE, 2007)

\section{Appendix 6}

Conceptual Strands in the Social Science Curriculum

Identity, Culture, and Organisation - Students learn about society and communities and how they function. They also learn about the diverse cultures and identities of people within those communities and about the effects of these on the participation of groups and individuals.

Place and Environment - Students leam about how people perceive, represent, interpret, and interact with places and environments. They come to understand the relationships that exist between people and the environment.

Continuity and Change - Students learn about past events, experiences, and actions and the changing ways in which these have been interpreted over time. This helps them to understand the past and the present and to imagine possible futures.

Sourcedfrom the New Zeaiand Curiculom, (MoE, 2007) 


\section{Appendix 7}

Drawn from Zumbrunn, Marrs and

Mewborn (2015)

Writing Self-Regulation Aptitude Scale

Before I start writing, I plan what I want to write.

Before I write, I set goals for my writing.

I think about who will read my writing.

I think about how much time I have to write.

I ask for help if I have trouble writing.

While I write, I think about my writing

goals.

I keep writing even when it's difficult.

While I write, I avoid distractions.

When I get frustrated with my writing, I

make myself relax.

While I write, I talk myself through what I need to do.

I make my writing better by changing parts of it.

I tell myself I did a good job when I write my best.

Self-Efficacy for Writing Scale (SEWS)

Statements - 4-point scale

I can spell words correctly

I can write complete sentences.

I can punctuate my sentences correctly.

I can think of many ideas for my writing.

I can put my ideas into writing.

I can think of many words to describe my ideas.

I can concentrate on my writing for a long time.

I can avoid distractions when I write.
I can keep writing even when it is difficult.

WKAM Questions for Questionnaires

What do good writers do when they write?

Why do you think some kids have trouble

writing?

When your teacher asks you to do writing for class, what kind of things can you do to help you plan and write?

Suppose you have a friend who has to write an argument for class. If your friend asks you what kinds of things are included in an argument, what would you tell her / him the parts of an argument are?

On a scale of 1(lowest) to 5 (highest), how confident are you that you can write an argument? Why do you think this?

How do you feel when you are given a writing assignment? What do you do when you are given a writing assignment? 
Appendix 8 Post Intervention Templates
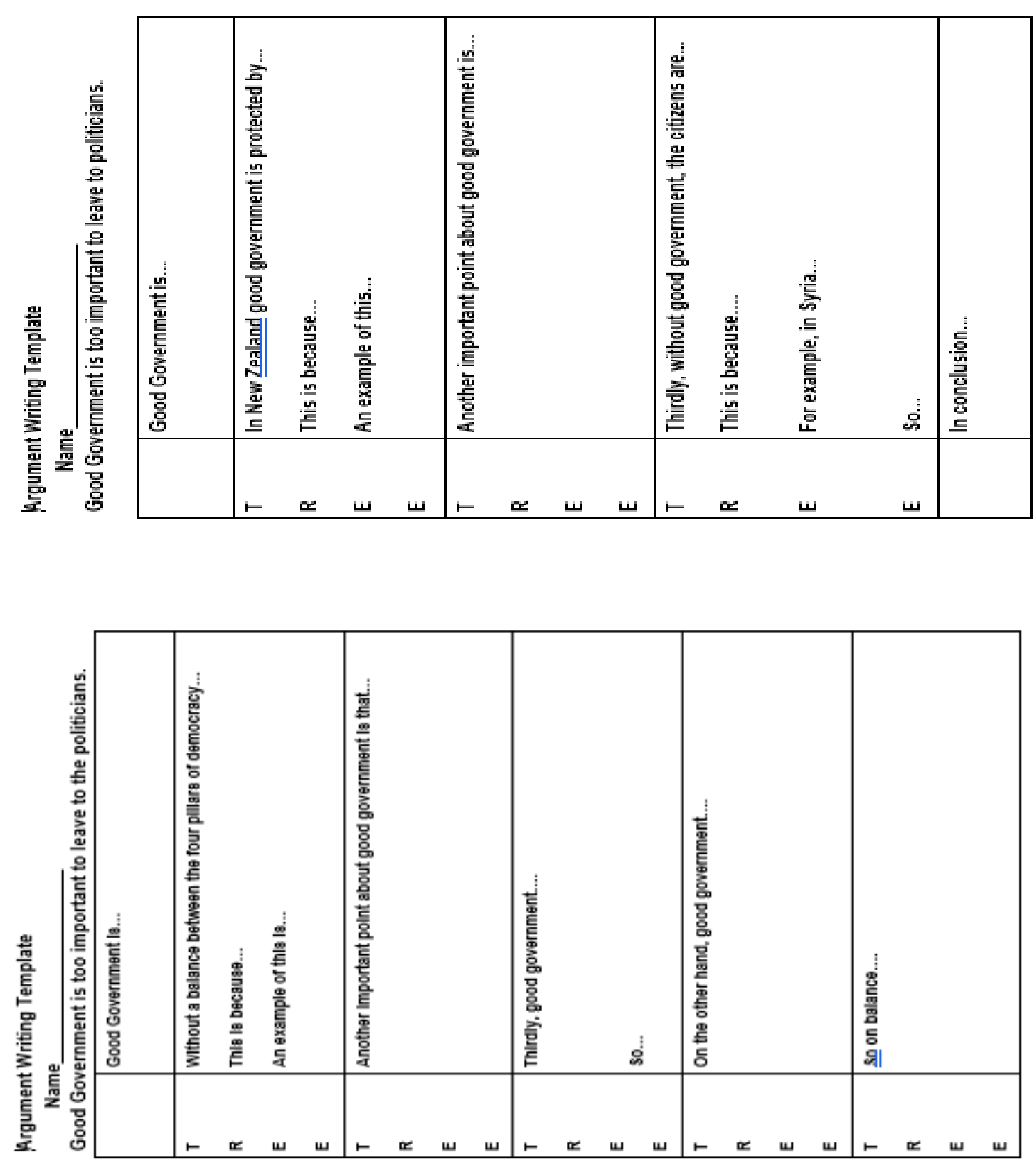


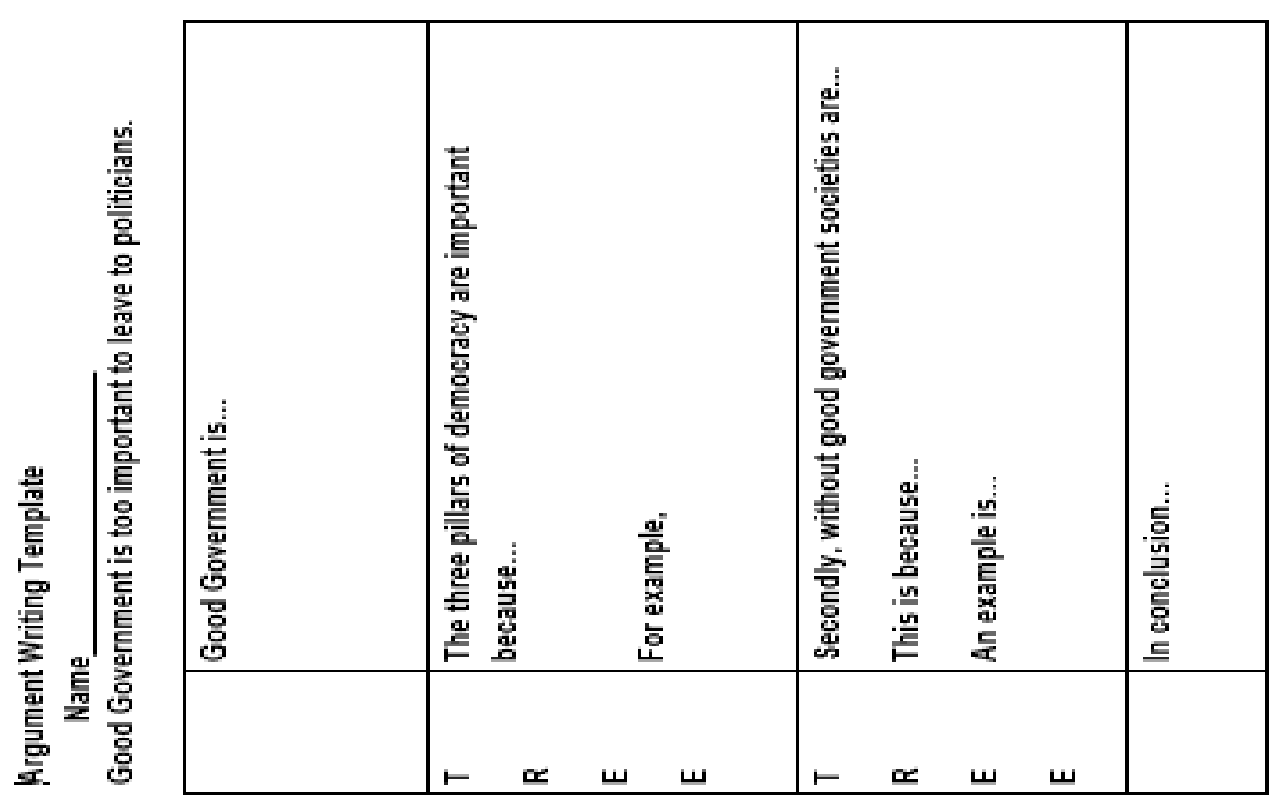




\section{Appendix 9}

Paired Samples Statistics

\begin{tabular}{|ll|l|l|l|l|}
\hline & & & & Std. Error \\
Mean
\end{tabular}




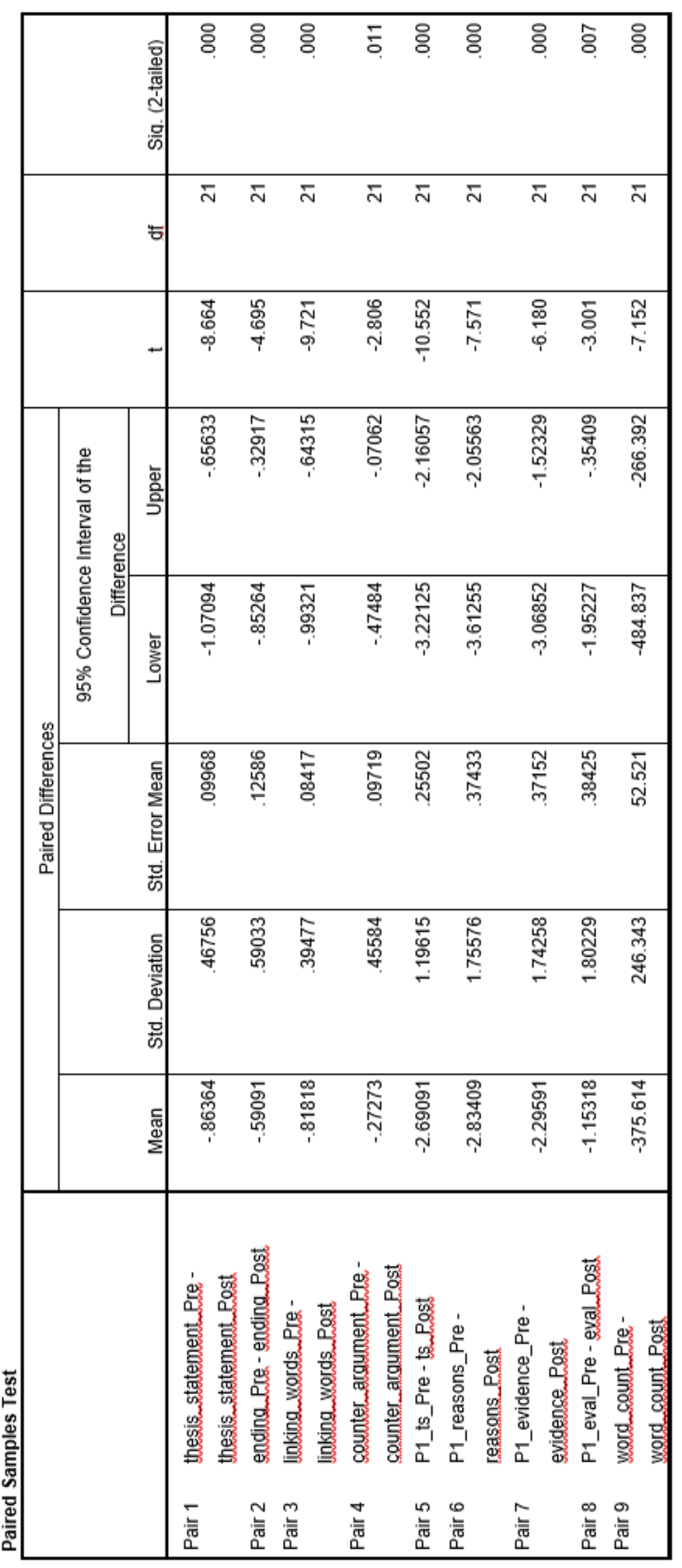


Appendix 10

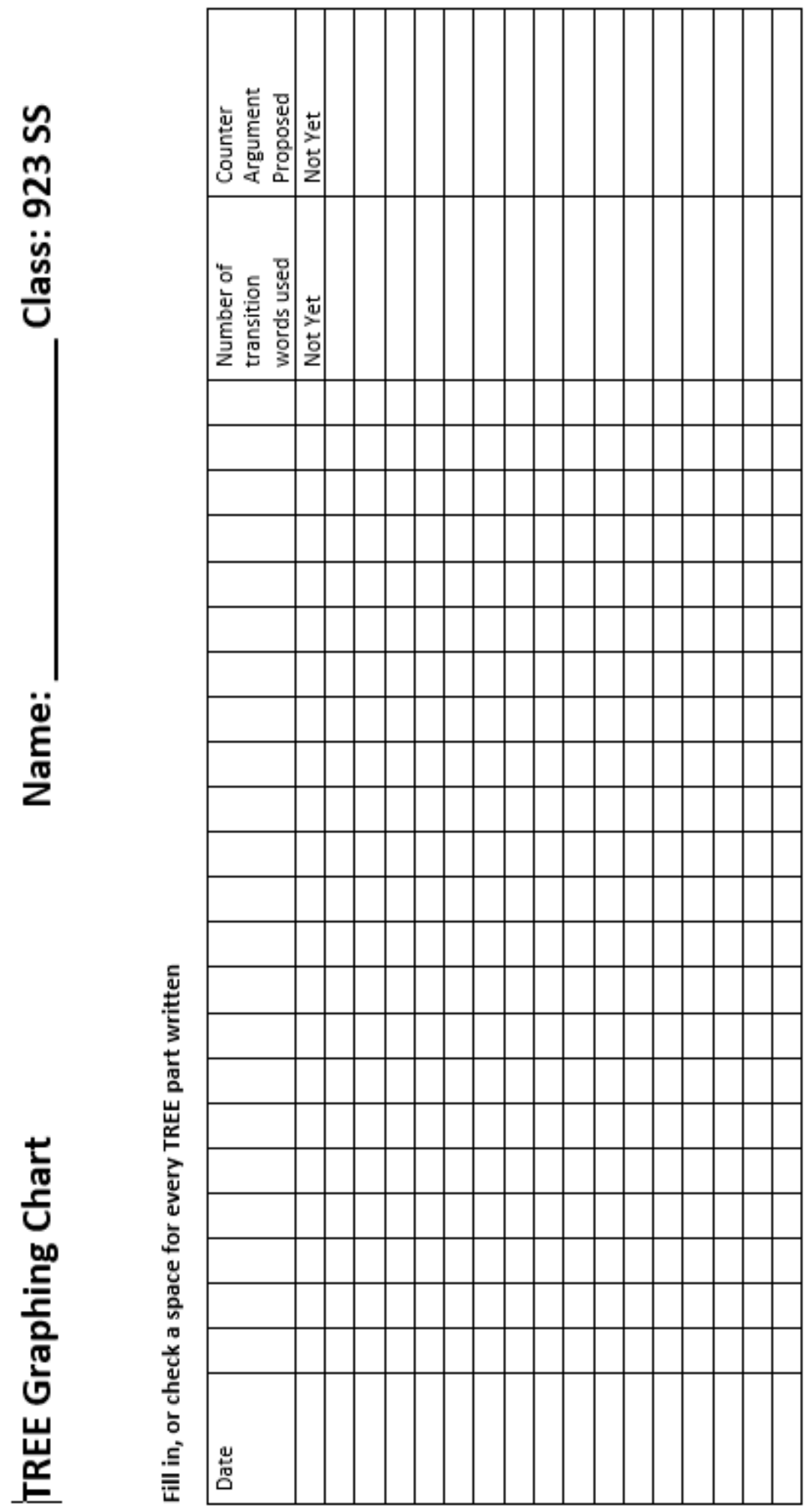


Appendix $11 \quad$ Initial Selective Sampling Data

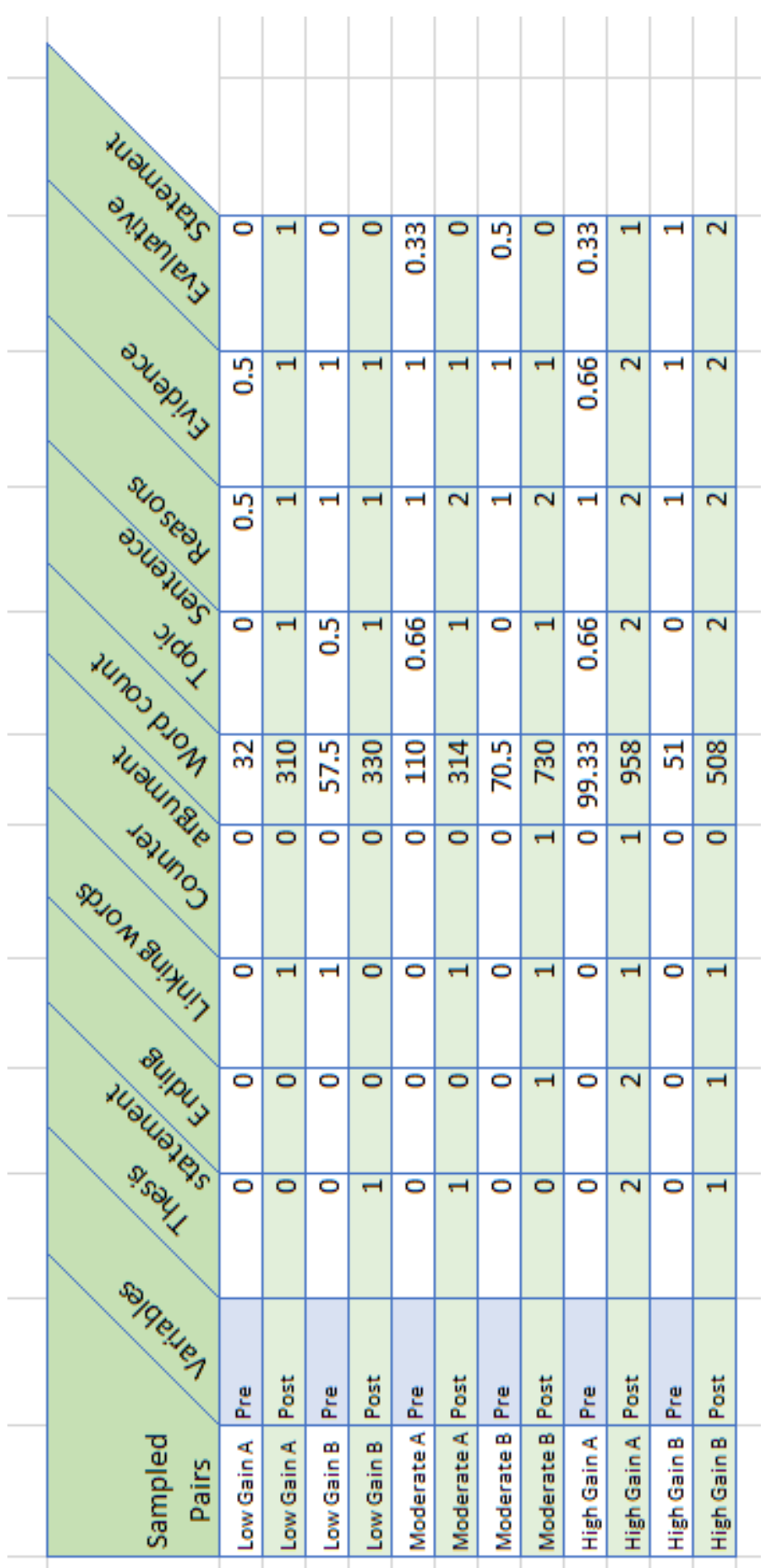




\section{Appendix 12}

Interview items

Please describe your thoughts about yourself as a writer.

Tell me something that has occurred that affected your confidence in yourself in writing.

If you were asked to rate your ability in writing on a scale of 1 (lowest) to 10 (highest), where would you be? Why?

When you are given a writing assignment, how does that make you feel?

Let's look at two samples of your writing. You wrote the first piece way back in Term 1. You wrote the second piece a few weeks ago, do you think that one is better or are they the same? [wait for response] Why? Please describe how you reacted when you compared the two samples of your writing.

What do good writers do when they write?

Why do you think some students have trouble writing?

If you were having difficulty with a writing assignment, what kinds of things would you do?

When your teacher asks you to write an argument essay for class, what kinds of things can you do to help you plan and write your paper?

Suppose you have a friend who has to write an argument essay for class. If your friend asks you what kinds of things are included in an argument essay, what would you say are the parts of a persuasive essay?

Is there anything else you'd like to comment on?

What could your teachers do to help you feel more confident in your writing abilities?

What do your parents tell you about writing?

What do your friends and classmates tell you about writing? 


\section{Appendix 13}

Qualitative Analysis

Tables showing Within-group Comparison

\section{Qualitative Analysis: Low Gain Group Comparison}

Differences are highlighted in red.

\begin{tabular}{|c|c|c|}
\hline Theme & Similarities and Differences & Evidence \\
\hline \multirow[t]{2}{*}{$\begin{array}{l}\text { Theme 1: } \\
\text { Seeing is } \\
\text { Believing }\end{array}$} & $\begin{array}{l}\text { Graphs increase motivation through } \\
\text { evidence of shift. } \\
\text { Writing sample comparison generates } \\
\text { confidence. }\end{array}$ & 1A seeing this I wanted to do better \\
\hline & $\begin{array}{l}\text { Graphs increase motivation through } \\
\text { evidence of shift. } \\
\text { Writing sample comparison generates } \\
\text { confidence }\end{array}$ & $\begin{array}{l}\text { 1B I am happy I didn't stay in this range, } \\
\text { and trying to go over there, so hopefully } \\
\text { next time I get an assignment I can go up } \\
\text { there }\end{array}$ \\
\hline \multirow[t]{2}{*}{$\begin{array}{l}\text { Theme 2: } \\
\text { Purpose }\end{array}$} & $\begin{array}{l}\text { Audience is important } \\
\text { Learning content matters }\end{array}$ & $\begin{array}{l}\text { 1A 'its strong 'cos a reader will agree' } \\
\text { '.. if I believe in it' }\end{array}$ \\
\hline & Audience is important & 1B 'it's not boring for the reader' \\
\hline \multirow{2}{*}{$\begin{array}{l}\text { Theme 3: } \\
\text { Problems } \\
\text { to } \\
\text { Overcome }\end{array}$} & Transcription issues & $\begin{array}{l}\text { 1A: 'what does this word mean? How to } \\
\text { spell it.'. 'more sophisticated' }\end{array}$ \\
\hline & $\begin{array}{l}\text { Transcription issues } \\
\text { Self-regulation issues } \\
\text { Ideation Issues }\end{array}$ & $\begin{array}{l}\text { 1B: 'I can get stuck for what to put' } \\
\text { 'grammar and spelling I need help } \\
\text { with' I panic' }\end{array}$ \\
\hline \multirow[t]{2}{*}{$\begin{array}{l}\text { Theme 4: } \\
\text { My } \\
\text { Agentic } \\
\text { Self }\end{array}$} & I can change things & $\begin{array}{l}\text { 1A: Without the strategies 'I didn't do as } \\
\text { well as I could' improvement caused by } \\
\text { practice, 'cause I worked a lot, } \\
\text { 'I don't read or write much out of class' }\end{array}$ \\
\hline & I might change things. & $\begin{array}{l}\text { 1B: 'I was having a good day' 'I was having } \\
\text { a bad day' } \\
\text { 'writing is not my best subject' }\end{array}$ \\
\hline
\end{tabular}


Qualitative Analysis: Medium Gain Group Comparison \$ +

\begin{tabular}{|c|c|c|}
\hline Theme & Similarities and Differences & Evidence \\
\hline \multirow[t]{2}{*}{$\begin{array}{l}\text { Theme 1: } \\
\text { Seeing is } \\
\text { Believing }\end{array}$} & $\begin{array}{l}\text { Graphs increase motivation through } \\
\text { evidence of shift. } \\
\text { Writing sample comparison generates } \\
\text { confidence. }\end{array}$ & $\begin{array}{l}\text { 2A 'My improvement has helped my } \\
\text { confidence' 'it makes me feel good' } \\
\text { 'makes me feel good because I can see } \\
\text { that I didn't do so good at the start of the } \\
\text { year but I did improve at the end of the } \\
\text { year' }\end{array}$ \\
\hline & $\begin{array}{l}\text { Graphs increase motivation through } \\
\text { evidence of shift. } \\
\text { Writing sample comparison generates } \\
\text { confidence }\end{array}$ & $\begin{array}{l}\text { 2B 'I'm in a good position, I still need to } \\
\text { learn and expand' }\end{array}$ \\
\hline \multirow[t]{2}{*}{$\begin{array}{l}\text { Theme 2: } \\
\text { Purpose }\end{array}$} & Skill in writing is helpful long term & $\begin{array}{l}\text { 2A 'It's gonoa be helpful in the future, } \\
\text { especially for exams, apparently' }\end{array}$ \\
\hline & Help in structure & $\begin{array}{l}\text { 2B 'when I was younger or last year, I was } \\
\text { like, where do I start?' }\end{array}$ \\
\hline \multirow{2}{*}{$\begin{array}{l}\text { Theme 3: } \\
\text { Problems } \\
\text { to } \\
\text { Overcome }\end{array}$} & Self-regulation issues & $\begin{array}{l}\text { 2A 'I'm not a confident writer' } \\
\text { 'I panic when I don't really have it' }\end{array}$ \\
\hline & $\begin{array}{l}\text { Self-regulation issues } \\
\text { Ideation Issues }\end{array}$ & $\begin{array}{l}\text { 2B 'I'm not really overly confident with, } \\
\text { like, what I'm meant to be writing' } \\
\text { 'I find it hard to come up with ideas' }\end{array}$ \\
\hline \multirow[t]{2}{*}{$\begin{array}{l}\text { Theme 4: } \\
\text { My } \\
\text { Agentic } \\
\text { Self }\end{array}$} & I can change things & $\begin{array}{l}2 A^{\prime} \text { I don't write that often, so its not as } \\
\text { easy as other subjects' } \\
\text { 'I use it in all my subjects' } \\
\text { 'it's following directions' } \\
\text { 'we find it easier to write now' } \\
\text { 'practice helps' }\end{array}$ \\
\hline & I can change things. & $\begin{array}{l}\text { 2B 'I can structure my writing better' } \\
\text { 'notes prepared..so I can get started' } \\
\text { 'you still have things to work on and } \\
\text { improve' }\end{array}$ \\
\hline
\end{tabular}




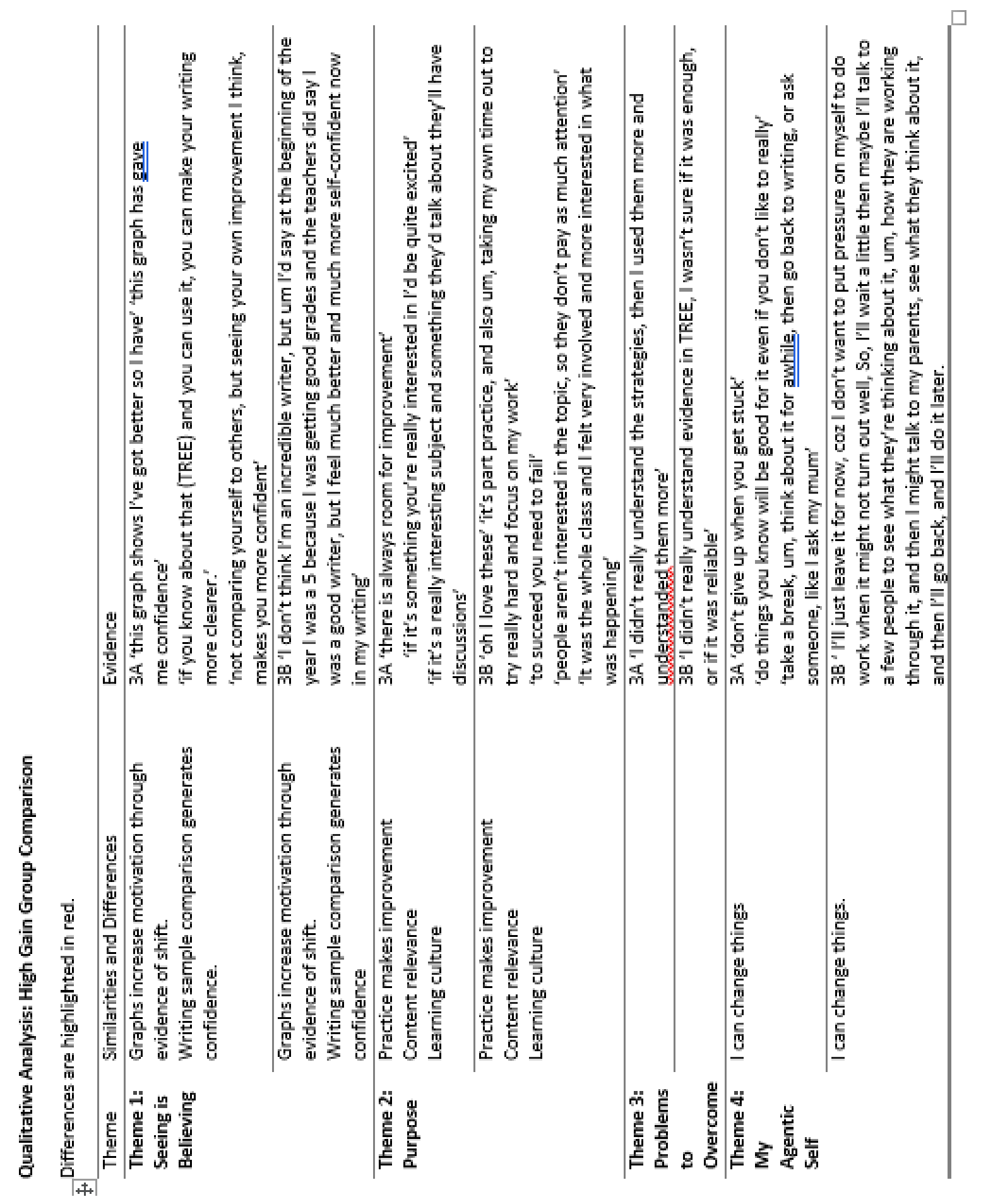

